\title{
Towards a versatile gas sensing platform with epitaxial graphene
}

Marius Rodner
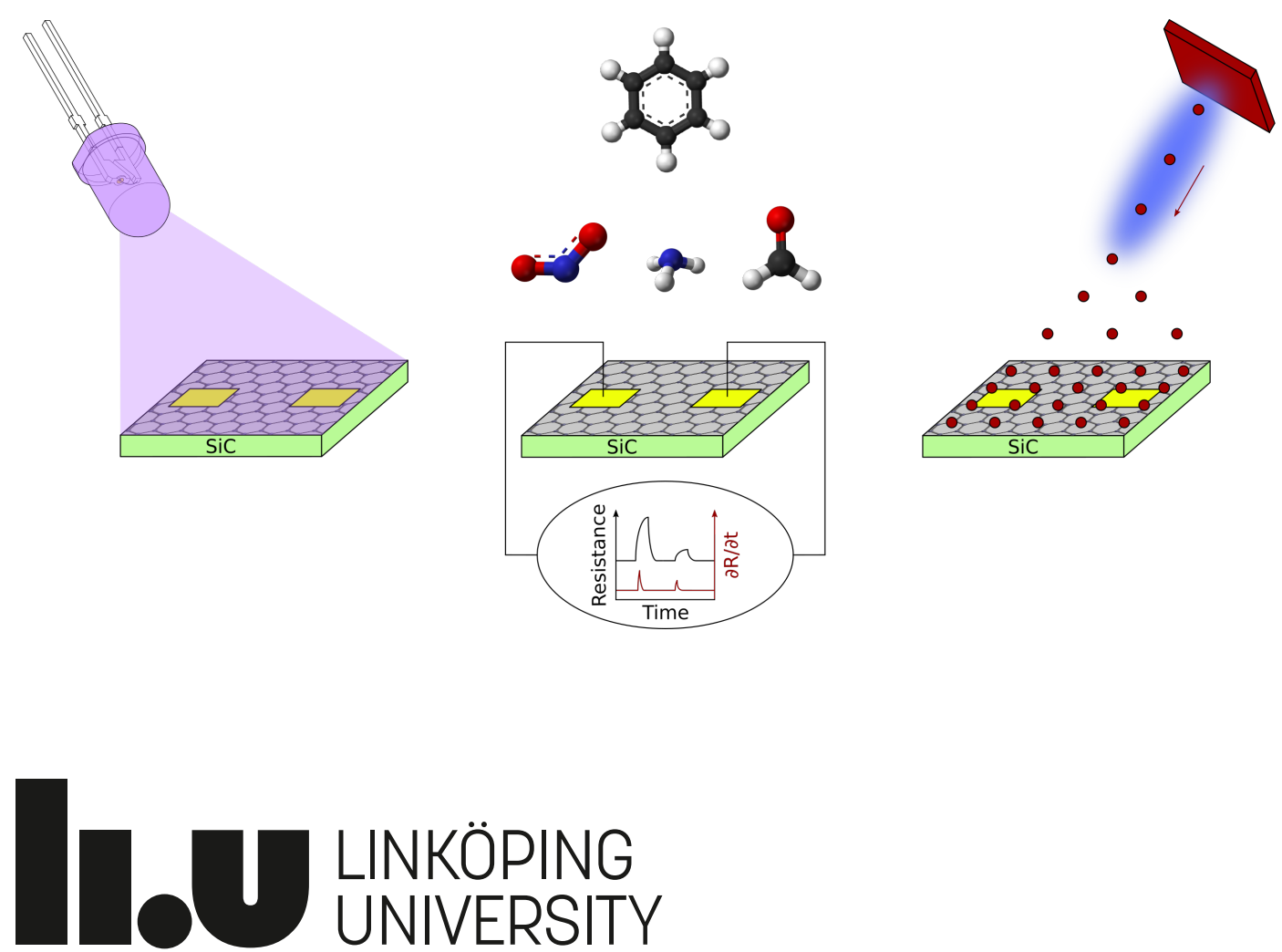
Linköping Studies in Science and Technology

Licentiate Thesis No. 1851

\title{
Towards a versatile gas sensing platform with epitaxial graphene
}

\author{
Marius Rodner
}
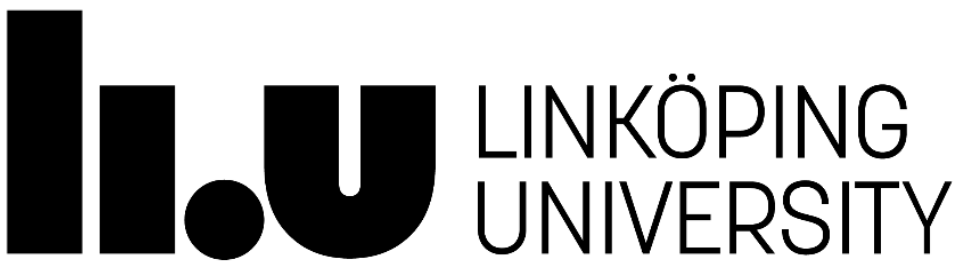

\author{
Applied Sensor Science Unit \\ Sensors and Actuators Division \\ Department of Physics, Chemistry and Biology \\ Linköping University, SE-581 83 Linköping \\ Sweden
}

Linköping 2019 
(C) Marius Rodner

Printed by LiU-Tryck, Linköping, Sweden, 2019

ISBN: 978-91-7519-010-5

ISSN: 0280-7971 


\section{ABSTRACT}

The work presented in this thesis focuses on how to utilize epitaxially grown graphene on $\mathrm{SiC}$ as a basis for ultra-sensitive gas sensor. Several approaches have been tested and evaluated to increase the sensitivity, selectivity, speed of response and stability and of the graphene based gas sensors with a focus on air quality monitoring applications. The graphene surfaces have been functionalized with different metal oxide nanoparticles and nanolayers using hollowcathode sputtering and pulsed laser deposition. The modified surface was investigated towards its topography, integrity and chemical composition with characterization methods such as AFM, Raman and XPS. Moreover, the binding energy was calculated with density functional theory for benzene and formaldehyde when reacting with pristine epitaxial graphene and iron oxide nanoparticle decorated graphene to verify the usefulness of this approach. The impact of environmental influences such as operating temperature, relative humidity and UV irradiation towards sensing properties was investigated as well. To further decrease time constants, the first-order time-derivative of the sensor's resistance is introduced as an alternative sensor signal and evaluated towards its applicability.

Applying these methods in laboratory conditions, sensors with a quantitative readout of single ppb benzene and formaldehyde were developed and time constants of less than one minute could be achieved with the first-order time-derivative signal. These results show promise to fill the existing gap of low-cost but highly sensitive and fast gas sensors for air quality monitoring. 



\section{Preface}

This thesis is part of my $\mathrm{PhD}$ studies in the Applied Sensor Science group, belonging to the Sensors and Actuators division of the department of Physics, Chemistry and Biology (IFM) at Linköping University. It is performed in close collaboration with other divisions at IFM, the department of Microtechnology and Nanoscience at Chalmers University of Technology, and the Laboratory for Measurement Technology at Saarland University, Germany. The goal of my research is to study gas sensors based on epitaxially grown graphene on silicon carbide and methods to turn them into a versatile gas sensing platform for applications with extreme sensitivity. This research is financially supported by the Swedish Foundation for Strategic research (SSF) for financial support through the grants GMT14-0077 and RMA15-024. During the course of research underlying this thesis, Marius Rodner was enrolled in Agora Materiae, a multidisciplinary doctoral program at Linköping University, Sweden. Research results are summarized, brought into context and then presented in the appended papers, preceded by an introduction to the scientific field and used research methods.

Marius Rodner

Linköping, August 2019 



\section{APPENDED PAPERS}

Paper 1 M. Rodner, J. Bahonjic, M. Mathisen, R. Gunnarsson, S. Ekeroth, U. Helmersson, I. G. Ivanov, R. Yakimova, J. Eriksson, Performance tuning of gas sensors based on epitaxial graphene on silicon carbide, Materials and Design, 153 (2018)

Paper 2 M. Rodner, D. Puglisi, S. Ekeroth, U. Helmersson, I. Shtepliuk, R. Yakimova, A. Skallberg, K. Uvdal, A. Schütze, J. Eriksson, Graphene Decorated with Iron Oxide Nanoparticles for Highly Sensitive Interaction with Volatile Organic Compounds, Sensors, 19 (2019)

Paper 3 M. Rodner and J. Eriksson, First-order time-derivative readout of epitaxial graphene-based gas sensors for fast determination of toxic air pollutants, in manuscript (2019)

\section{Author's contribution to appended papers}

Paper 1 I evaluated and interpreted all measurement data and wrote the manuscript.

Paper 2 MR conceived and performed all gas and AFM measurements, evaluated and interpreted the data and wrote the main part of the manuscript.

Paper 3 MR conceived and performed all measurements, evaluated and interpreted the data and wrote the manuscript.

Published articles have been reprinted with the permission of the copyright holders. 


\section{OTHER RELATED PUBLICATIONS}

Paper A M. Rodner, D. Puglisi, R. Yakimova, J. Eriksson, A Platform for Extremely Sensitive Gas Sensing: 2D Materials on Silicon Carbide, TechConnect Briefs, (2018)

Paper B M. Rodner, D. Puglisi, S. Ekeroth, U. Helmersson, I. G. Ivanov, R. Yakimova, K. Uvdal, A. Schütze, J. Eriksson, Iron Oxide Nanoparticle Decorated Graphene for Ultra-Sensitive Detection of Volatile Organic Compounds, Proceedings, 2 (2018)

Paper C P. Darshni Kaushik, M. Rodner, G. B. V. S. Lakshmi, I. G. Ivanov, G Greczynski, J. Palisaitis, J. Eriksson, P. Solanki, A. Aziz, A. M. Siddiqui, R. Yakimova, M. Syväjärvi, G. R. Yazdi, Surface Functionalization of epitaxial graphene using ion implantation for sensing and optical applications, Carbon, submitted (2019) 


\section{ACKNOWLEDGEMENTS}

First of all, I want to thank my supervisor Jens Eriksson for accepting me into his group and guiding me through this scientific journey on the search for the ultimate gas sensor. I am grateful for your patience, especially, when I come knocking again asking allegedly silly questions, and your support with so many scientific questions. Research is not all about science and, therefore, thank you also for being a good friend.

Moreover, I would like to thank all the former and current members of our small research unit, Anita Lloyd Spetz, Donatella Puglisi, Francesca Santangelo, Jasna Bahonjic, Lida Khajavizadeh, Manuel Bastuck, Mike Andersson, Peter Möller and Yuki Hasegawa. Even the most interesting project would not be any fun without a good work environment. So thank you all for all the Fikas, country dinners, work and non-work related trips around the world, group activities and of course a lot of scientific and non-scientific discussions. A special thanks to Donatella, who took care of me when I was new to this group and Sweden. And also to Mike for his company in and outside of IFM and without whom our laboratory would not function at all. Moreover, I want to thank our current and former master students Adam Icardi and Marcus Mathisen for their contributions to this work.

I would also like to thank all the people I have collaborated with during this project at IFM and also at Chalmers University. Thank you for all the help and support from sample preparations, over characterizations to evaluations and discussions.

For the opportunity to continue a collaboration with my old group at Saarland University, I want to thank Andreas Schütze and the members of his Laboratory for Measurement Technology group. A very special thanks to Manuel Bastuck, who is only a part time member of our group here in Linköping and spends most of his time in Germany. Thank you for taking care of me and my measurement 
wishes when I came for visits to the old lab and all the help and discussions about our courses, papers, ongoing work, theses and life in general.

Many thanks to my friends from Agora, our lunch group and our climbing group. I am really glad to be friends with so many Swedish and international $\mathrm{PhD}$ students and Postdocs. It never gets boring and someone is always up for Fika or beers, over which it is much less frustrating to talk about research and life if it doesn't work as it should. Of course I also want to thank my 'old' friends from Germany for their support. Although I am still waiting for some of you guys to show up here!

Last and most important, I want to thank my family and my girlfriend Lisa. Thank you very much for so much support and motivation both from Germany and on site here in Linköping. This whole expedition would not be possible without you. 


\section{Table of contents}

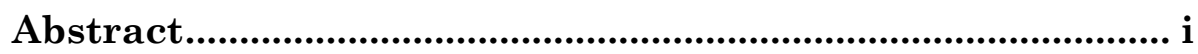

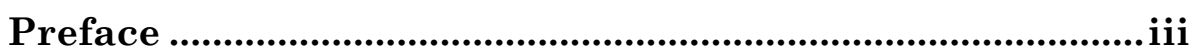

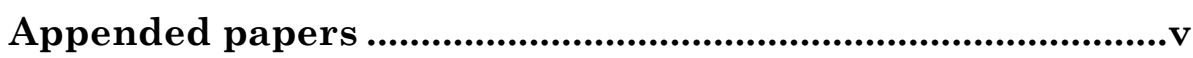

Other related publications............................................................. vi

Acknowledgements......................................................................... vii

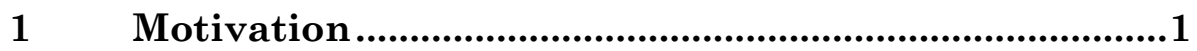

2 Theory and Concepts .........................................................5

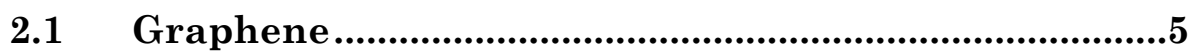

2.1.1 Electronic properties.................................................

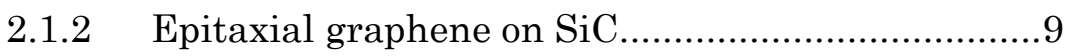

$2.2 \quad$ Graphene as gas sensor ...............................................10

2.2.1 Sensor performance tuning ……………………....11

2.2.2 Sensing mechanism ................................................ 13

$3 \quad$ Experimental Methods ………………….....................15

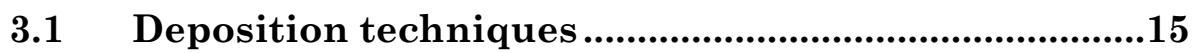

3.1.1 Thermal evaporation ………………………….....15

3.1.2 Sputter deposition..................................................17

3.1.3 Pulsed Laser Deposition ..........................................20

3.2 Characterization methods ............................................22

3.2.1 Atomic Force Microscopy ………………………......22

3.2.2 Raman spectroscopy ………………………….......23

3.2.3 X-ray photoelectron spectroscopy …………….......25

3.2.4 Density functional theory ……………………......25

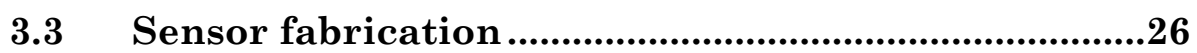

3.3.1 Graphene growth ..................................................26

3.3.2 Sensor mounting ..................................................28

3.3.3 Data acquisition ........................................................ 30 
3.4 Gas mixing apparatus ............................................... 31

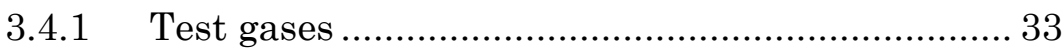

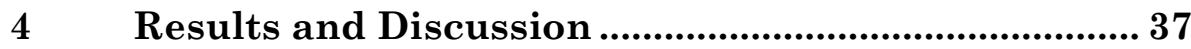

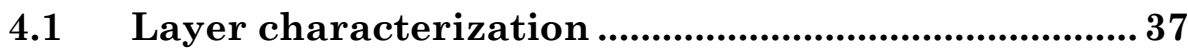

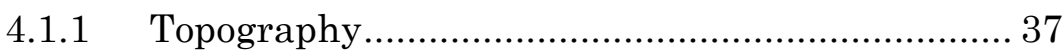

4.1.2 Structural integrity ............................................ 40

4.1.3 Chemical composition ........................................ 42

4.1.4 Theoretical considerations ................................... 43

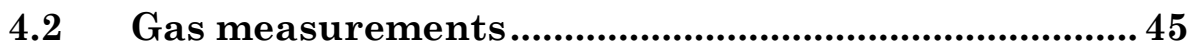

4.2.1 Influence of temperature .................................. 46

4.2.2 Influence of humidity ......................................... 50

4.2.3 Influence of UV irradiation............................... 52

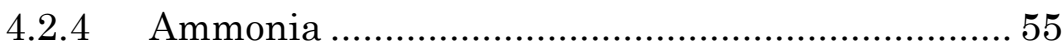

4.2.5 Nitrogen dioxide.............................................. 56

4.2.6 Benzene and Formaldehyde................................ 57

4.3 First-order time-derivate signal ...............................60

4.3.1 Influence of exposure and relaxation time ........... 62

4.3.2 Environmental influences................................... 64

4.3.3 Time constants ............................................... 66

$5 \quad$ Conclusions and outlook ............................................ 71

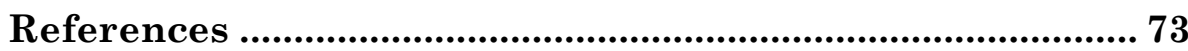

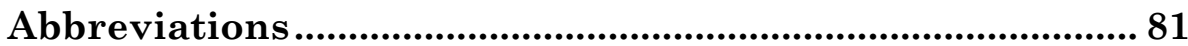




\section{Motivation}

According to the World Health Organization (WHO), several toxic air pollutants exceed the recommended exposure levels in more than $80 \%$ of the monitored urban areas [1]. Bad air quality is linked to various health impacts such as eye and skin irritation but also respiratory problems, cancer, or even death. It was estimated that poor air quality is accountable for more than 8 million deaths per year [2] also inflicting a yearly financial burden to the European region of about 1.6 trillion US dollars [3].

A proper way of detection needs to be established to be able to detect even trace amounts of hazardous gases. When it comes to the detection of carcinogenic volatile organic compounds (VOCs) like benzene $\left(\mathrm{C}_{6} \mathrm{H}_{6}\right)$ and formaldehyde $\left(\mathrm{CH}_{2} \mathrm{O}\right)$ at relevant levels, there are commercial instruments available, which are, however, large, complex, and expensive. Small low-cost sensor systems, on the other hand, suffer from limited sensitivity and selectivity [4], [5]. A portable low-cost sensor capable of detecting VOCs at single digit parts per billion $\left(\mathrm{ppb}^{1}\right)$ or even lower would thus be a breakthrough in the field of air quality monitoring (AQM).

Two-dimensional materials like graphene exhibit several outstanding properties which enables the fabrication of sensor devices that can be used for detection of very small gas concentrations.

One way to strongly increase the sensitivity and, potentially, selectivity of a gas sensor is the combination of different materials or the decoration of a sensitive transducer with a selective metal oxide. This was especially studied using graphene as transducer due to its very good sensing properties. For example, it has been shown that decorating the graphene surface with metal or metal oxide nanoparticles can lead to an increased sensitivity and selectivity towards gases like nitrogen dioxide $\left(\mathrm{NO}_{2}\right), \mathrm{C}_{6} \mathrm{H}_{6}$ and $\mathrm{CH}_{2} \mathrm{O}$ [6]. Moreover,

\footnotetext{
${ }^{1} \mathrm{ppb}$ refers here to the ratio in volume. Also known as $\mathrm{ppb}_{\mathrm{v}}$.
} 


\section{Motivation}

iron oxide decorated multiwall carbon nanotubes, a close relative to graphene, in combination with UV (ultraviolet) irradiation [7], and zinc oxide fibers [8] exhibit promising sensitivity towards $\mathrm{C}_{6} \mathrm{H}_{6}$. All these sensors are able to detect $\mathrm{C}_{6} \mathrm{H}_{6}$ down to tens of ppb, but not reliably lower. High sensitivity alone though is not sufficient to produce a useful gas sensor. Other properties such as stability, selectivity and fast time constants are also necessary. Especially for indoor AQM, a sensor needs to be sensitive, selective, stable and it must have a high enough sampling rate to allow real-time monitoring with high resolution [9], [10]. Another method to increase sensitivity and decrease time constants is the irradiation with UV light which has been shown for many different material/gas combinations [11].

To speed up the sensor response, usually the sensor is irradiated with a light source during the gas measurement or operated at elevated temperatures. A different method is the use of the sensor signal's first-order time-derivative that was shown to drastically decrease the time constants [12].

The creation of a portable low-cost sensor capable of quickly detecting VOCs at concentrations of interest by combining all these approaches would thus be a breakthrough in the field of air quality monitoring.

This thesis summarizes and elaborates upon the work published in Paper 1-3. Paper 1 discusses ways to improve the performance of gas sensors based on graphene epitaxially grown on silicon carbide with metal oxide nanoparticle decoration, UV irradiation and a smart sensor readout utilizing the first-order time-derivative of the sensor's resistance to evaluate them for AQM applications.

Paper 2 focuses on the first described approach, the surface decoration with iron oxide nanoparticles and the implications for gas sensing properties towards $\mathrm{C}_{6} \mathrm{H}_{6}$ and $\mathrm{CH}_{2} \mathrm{O}$ in the concentration range from parts per million down to parts per billion to create ultra-sensitive gas sensors for hazardous VOCs. 
Paper 3 then focuses on the utilization of the first-order timederivative of the sensor's resistance as a new sensor signal, its implications for time constants and its stability towards external influences to enhance speed of response and stability of the tested gas sensors. 



\section{Theory and Concepts}

This chapter discusses the general properties of graphene, its peculiarities if grown on silicon carbide ( $\mathrm{SiC}$ ) and possible surface modifications to tailor it towards an optimized gas sensor.

\subsection{Graphene}

The existence of graphene was already predicted in 1947, but it took until 2004 to be able to produce a free-standing, monoatomic layer of graphene that could be studied with regards to its special properties [13]. Since then, a lot of research was conducted and graphene became the most studied two-dimensional material until now. Its two-dimensional structure consists of an arrangement of hexagonal covalently bonded carbon atoms forming a honeycomb structure. The planar structure is due to $\mathrm{sp}^{2}$ hybridization of orbitals between carbon atoms. Three out of four orbitals are $\mathrm{sp}^{2}$ hybridized, leading to a strong covalent $\sigma$-bonds with a high bonding energy of $\sim 5.9 \mathrm{eV}$ in the trigonal system. These bonds are responsible for the flat structure of graphene and the exceptional structural strength. Each carbon atom has four valence electrons available. The solitary porbital forms aromatic п-bonds with the adjacent carbon atoms [14]. These delocalized electrons form the valence and conduction bands in graphene and give rise to the materials conductivity. A schematic depiction of the honeycomb lattice structure of graphene and its corresponding reciprocal counterpart are shown in Figure 2.1. The lattice vectors of the real space unit cell are described as

$$
a_{1}=\frac{3 a}{2} \hat{x}+\frac{\sqrt{3} a}{2} \hat{y} ; \quad a_{2}=\frac{3 a}{2} \hat{x}-\frac{\sqrt{3} a}{2} \hat{y}
$$

where $a$ is the distance between adjacent carbon atoms (1.42 $\AA$ ). The hexagonal lattice of graphene can be described as a combination of two triangular sublattices, A and B. The primitive cell contains two atoms in total, one from each sublattice. 
Direct lattice

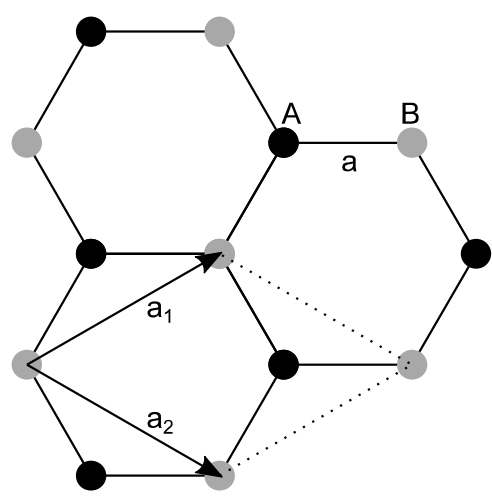

Reciprocal lattice

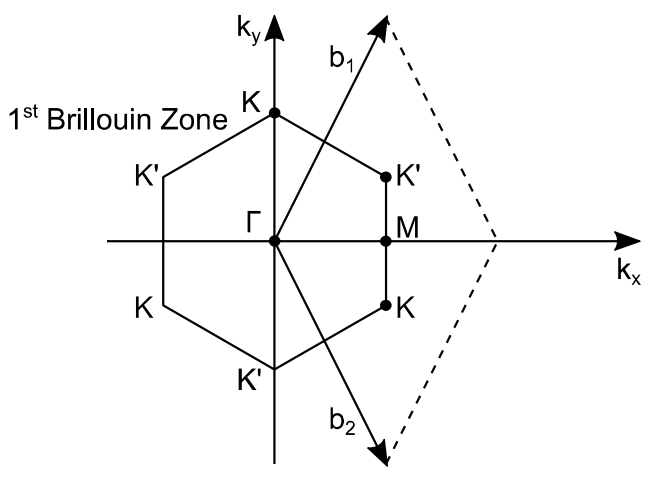

Figure 2.1: Left: Real space honeycomb lattice of graphene, consisting of two overlapping triangular sublattices A (black atoms) and $\mathrm{B}$ (grey atoms). The lattice vectors $\mathrm{a}_{1}$ and $\mathrm{a}_{2}$ form the primitive cell together with the dotted lines. Right: Reciprocal lattice with the $1^{\text {st }}$ Brillouin zone. Adapted from [15].

The $1^{\text {st }}$ Brillouin zone (BZ) is shown in the reciprocal lattice, which is defined by the reciprocal lattice vectors $b_{1}$ and $b_{2}$. The corners of the hexagonal $1^{\text {st }} \mathrm{BZ}$ are marked by six points, with only two non-equivalent points $\mathrm{K}$ and $\mathrm{K}$ ', due to the two sublattices A and B. These six points are called Dirac points. The reciprocal vectors and the Dirac points can be calculated using

$$
b_{i} a_{j}=2 \pi \delta_{i j}
$$

where $\delta_{\mathrm{ij}}$ is the Kronecker delta leading to

$$
\begin{gathered}
b_{1}=\frac{2 \pi}{3 a} \hat{x}+\frac{2 \pi}{\sqrt{3} a} \hat{y} ; \quad b_{2}=\frac{2 \pi}{3 a} \hat{x}-\frac{2 \pi}{\sqrt{3} a} \hat{y} \\
K=\frac{2 \pi}{3 a} \hat{x}+\frac{2 \pi}{\sqrt{3} \cdot 3 a} \hat{y} ; \quad K^{\prime}=\frac{2 \pi}{3 a} \hat{x}-\frac{2 \pi}{\sqrt{3} \cdot 3 a} \hat{y}
\end{gathered}
$$

2D graphene can also be the starting point for other interesting carbon allotropes (see Figure 2.2). It can be wrapped into 0D fullerenes (also referred to as 'Buckyball'), rolled into 1D nanotubes (also 


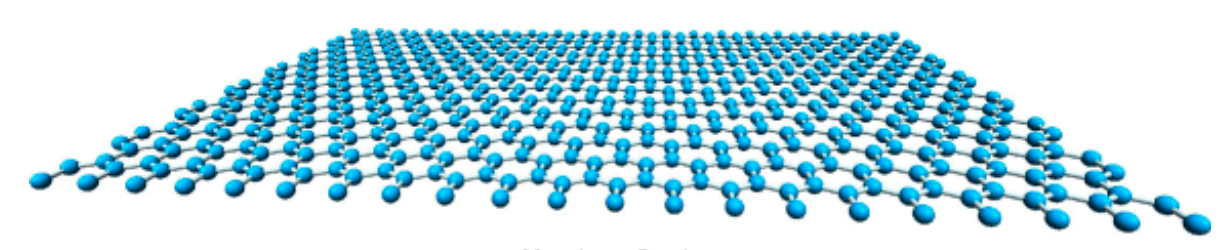

Monolayer Graphene

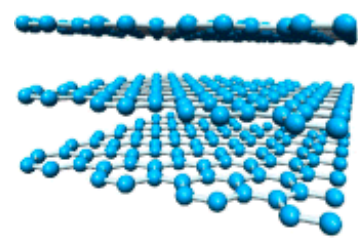

Multilayer Graphene

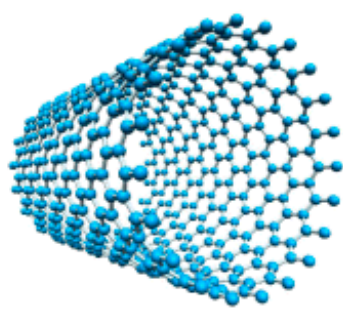

Carbon Nanotube

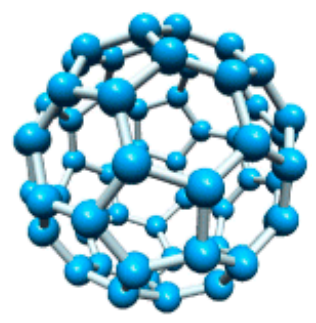

Buckyball

Figure 2.2: Different structures formed out of graphene [16].

referred to as 'CNTs') or stacked into 3D graphite (also referred to as 'Multilayer graphene' if only a low number of layers is used). Each structure with its peculiar properties is used in different fields of research and applications.

\subsubsection{Electronic properties}

Graphene has some outstanding properties like high electrical conductivity $\left(\sim 10^{8} \mathrm{~S} / \mathrm{m}\right)$, high melting point $(4510 \mathrm{~K})$, high thermal conductivity (2000-5000 W/(m K)), high current density $\left(\sim 1.6 \cdot 10^{9} \mathrm{~A} / \mathrm{cm}^{2}\right)$ and a high electron mobility $\left(2 \cdot 10^{5} \mathrm{~cm}^{2} /(\mathrm{V} \mathrm{s})\right.$ at electron density $\sim 2 \cdot 10^{11} \mathrm{~cm}^{-2}$ ) [17]. Figure 2.3 shows the low energy band structure for graphene with the Dirac points. At the six Dirac points, valence and conduction band meet in the reciprocal space. The energy dispersion is linear close to the Dirac points at low energies $|\mathrm{E}|<3 \mathrm{eV}$ and is similar to that of ultra-relativistic particles with zero rest mass like photons. For such particles, the Schrödinger equation can be simplified into the 2D Dirac equation which describes the behavior of massless Dirac fermions. This is also the reason why the $\mathrm{K}$ and $\mathrm{K}$ ' points are called Dirac points. The linear 


\section{Theory and Concepts}

dispersion creates a conical shape in reciprocal space, the so-called Dirac cone. The density of states (DOS) can then be calculated as

$$
\operatorname{DOS}(E)=\frac{2|E|}{\pi\left(\hbar v_{F}\right)^{2}}
$$

$\hbar$ is the so-called Planck constant and $v_{F}$ is the Fermi velocity. Electron hopping is the dominating charge transfer mechanism in graphene and therefore the charge carriers move at the Fermi velocity $\left(\sim 10^{6} \mathrm{~m}^{-1}\right)[15]$. The DOS is linear with energy and vanishes at the Dirac point. In theory this means that, at absolute zero, graphene is an electrically insulating material with infinite resistance at the Dirac point. Since there is no band gap, graphene is often referred to as a zero-bandgap semi-metal. In practice, there are other factors such as spatial charge disorder which complicate this relation though. Experiments at the Dirac point show not infinite, but finite resistance, with the maximum resistance of graphene being controversial with different theories predicting different values [18].

It is important to note that multilayer graphene can exist in the AB (Bernal) or the AA stacked form. In the AA stacked form, all layers are perfectly aligned, whereas in the Bernal stacked form, half of the atoms lie directly over the center of a hexagon in the lower graphene sheet, and half of the atoms lie over an atom. This

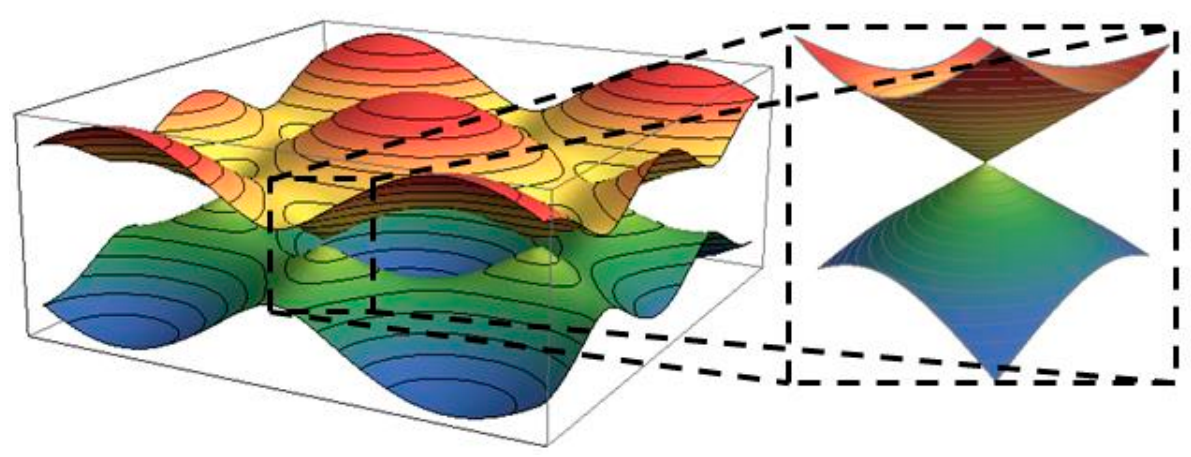

Figure 2.3: Dirac points in graphene with the electronic dispersion of the honeycomb lattice in terms of (zoomed in) the energy spectrum of finite values. 
is very important for electrical properties of the graphene sheets [15]. Moreover, the binding energy between $\mathrm{AB}$ stacked layers is higher compared to AA stacked layers, leading to a more stable structure [19].

\subsubsection{Epitaxial graphene on SiC}

$\mathrm{SiC}$ is a crystal comprised of layers of tetrahedrally bonded $\mathrm{Si}-\mathrm{C}$ atom pairs. The most commonly used polytypes of SiC for graphene growth are $6 \mathrm{H}-\mathrm{SiC}$ and $4 \mathrm{H}-\mathrm{SiC}$. The letter $\mathrm{H}$ indicates the hexagonal crystal structure and the numbers 6 and 4 define the number of Si-C pairs stacked per unit cell. SiC has two different surface terminations: Si-face (Si atoms) or C-face (C atoms). For the growth of monolayer graphene, the Si-terminated surface state (0001) is usually used, as it exhibits a slower and more controlled growth process [20]. C-terminated SiC (0001) leads to multi-layered and more inhomogeneous growth of graphene instead [21]. Therefore, the Siface is used for applications where high quality graphene is needed, such as Quantum Hall Effect (QHE) devices [22], [23] or gas sensors.

If $\mathrm{SiC}$ is heated to sufficiently high temperatures, Si-atoms sublimate and leave a carbon-rich layer beneath which eventually forms graphene. The growth is explained in more detail in section 3.3.1. The very first layer of graphene forms the so-called buffer layer, where around $30 \%$ of the carbon atoms are still covalently bond to the $\mathrm{SiC}$ bulk, turning it into an insulating layer. It is also often referred to as zero-layer graphene. The second layer then forms the freestanding conducting monolayer of graphene. Figure 2.4 shows a schematic of the grown graphene lattice on top of $\mathrm{SiC}$ with the buffer layer in between. Nevertheless, the graphene layer is still influenced electrically by the buffer layer and the $\mathrm{SiC}$ bulk. The buffer layer has a distance of only $<4 \AA$ to the graphene layer and acts as an electron donor leading to intrinsic n-doping in the order of $\mathrm{n} \approx 10^{13} \mathrm{~cm}^{-2}[24]$. Moreover, it has a high density of states. 


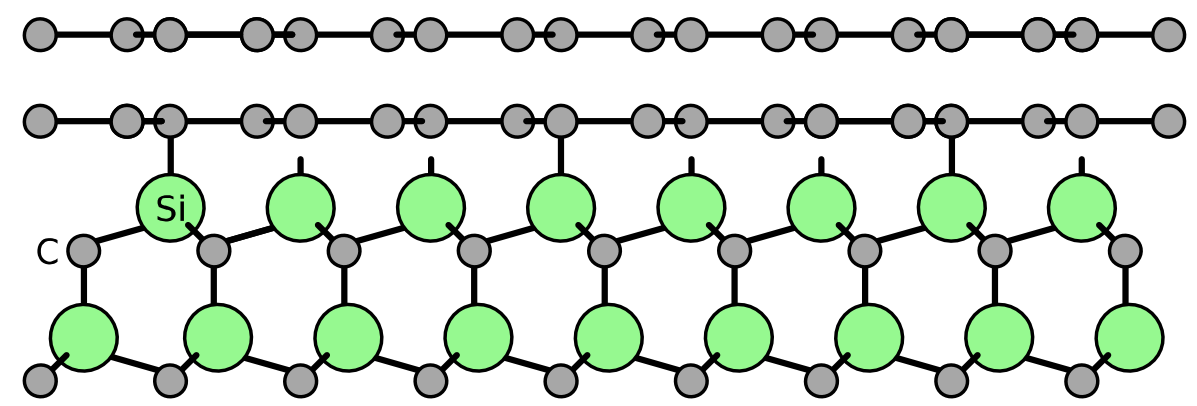

Figure 2.4: Schematic of epitaxial graphene on SiC.

The SiC bulk also affects the doping of graphene in the same direction as the buffer layer [21]. The buffer layer reduces the mobility in epitaxial graphene (EG) compared to exfoliated graphene due to the introduction of charges and scattering centers. To eliminate the influence of the buffer layer, the covalent bonds between buffer and $\mathrm{SiC}$ can be removed through the intercalation of, for example, hydrogen which will decouple the buffer layer into a freestanding graphene layer [21]. To produce monolayer graphene in this manner it is necessary to perform the intercalation step on $\mathrm{SiC}$ that has been processed to have just the buffer layer with no graphene on top.

\subsection{Graphene as gas sensor}

Besides the already mentioned properties, its exceptionally low electronic noise makes graphene very promising for sensing applications, such as strain sensors, electrical sensors and chemical sensors including gas sensors [17]. Fluctuations due to thermal motion of charges and defects lead to intrinsic noise, limiting the detection resolution of gas sensors. Schedin et al. demonstrated already in 2007 that graphene can be used to detect single atoms/molecules [25]. Adsorbates can attach to a graphene surface, alter the local carrier concentration and, thus, change the resistance accordingly. Since then, a lot of research has been conducted to utilize graphene as 'the ultimate gas sensor'. It was found that when using graphene 
as a sensitive layer, the amount of layers does greatly affect the sensor performance [26]. This is especially true for EG on SiC, as the sensitivity depends on the band structure which in turn depends on the number of layers, as SiC exhibits Bernal stacking of graphene layers. Moreover, graphene has been found to be very sensitive towards some gases like ammonia $\left(\mathrm{NH}_{3}\right)$ or $\mathrm{NO}_{2}$, but needs functionalization to fully exploit its potential [27]. Due to its high sensitivity towards many gases, graphene suffers from poor selectivity. At the same time, graphene exhibits poor interaction with several gases of interests in AQM, such as VOCs and also exhibits slow adsorption and desorption, leading to long response and recovery times. Moreover, its low number of dangling bonds on the surface limits the chemisorption of the target gases, thus limiting the sensitivity [28].

\subsubsection{Sensor performance tuning}

There are many different ways to overcome the limitations of pure graphene gas sensors. Usually, the surface is functionalized with doping, decorated with other materials, combined into a compound material, defects are generated through etching or ion irradiation to generate adsorption sites or UV irradiation is applied to increase the surface energy of the sensing layer.

The enhancement of sensitivity and decrease of time constants using UV irradiation was shown for many different material/gas combinations [11]. The irradiation with light allows energized photons to interact with the target gas or sensing material. This interaction highly depends on the possibility to adsorb energized photons. Thus the photon energy level has to be compatible. This in turn means that the interaction depends on the wavelength of the irradiation source and might be enhanced for one wavelength, but has no effect at all for other wavelengths. The photon interaction can help to split up gas molecules into detectable gas atoms or it can help to clean the sensor surface from the adsorbed gas and ac- 


\section{Theory and Concepts}

tivate adsorption sites. For example, it was reported that UV irradiation can be attributed to cleaning of the graphene surface, thus freeing active sites for target gas adsorption [29]. Unfortunately, this method does not work for all material/gas combinations, making it a useful, but not very versatile add-on.

The most common and extensively studied approach is to work with graphene itself and turn it into a hybrid structure with metal oxides. Metal oxides are very well studied in the gas sensor community and are dominating in industrial applications due to their advantages like low cost and controlled production. Having the optimal metal oxide and target gas combination already leads to a very good sensor performance. The sensitivity towards a certain gas can drastically be increased by increasing the surface-to-volume ratio of the sensing layer as a larger detection area per unit volume results in a higher adsorption of gas molecules per volume, thus leading to more material gas interaction. Therefore, nano-sized structures are often used in combination with highly sensitive materials. Combining the advantages of sensitive and more selective metal oxides with sensitive and low noise graphene, can lead to very promising new sensor hybrids [30], [31], where the surface chemistry is controlled by the metal oxide nanostructure, whereas the graphene is utilized as a highly sensitive transducer. Moreover, graphene can be turned into graphene oxide or wrapped into CNTs. This new material is then again $\mathrm{p}$ as a transducer and functionalized with different sensitive materials. In this work, graphene was decorated with different metal oxide nanoparticles (NPs) and nanolayers (NLs).

It was also shown that the sensitivity of graphene can be optimized by introducing vacancies or doping impurities into the lattice [32]. This can lead to higher sensitivities but normally entails a higher noise level, due to local disruptions of the $\mathrm{sp}^{2}$ hybridization.

One option where no additional equipment or actual functionalization is needed is the use of transient or secondary data, generated during the measurement. A common approach, usually applied for metal oxide semiconductor (MOS) or field effect transistor (FET) 
devices, is the operation mode called temperature cycled operation (TCO) [33], [34]. A high operation temperature is often desirable, as it accelerates reactions on the sensor like ad- and desorption, influences speed and repeatability, and can change the catalytic activity of the sensor surface. Even more information can be gained by quickly cycling between different temperatures to create non-equilibrium states that can be used to enhance sensitivity and selectivity [35]. If the sensor does not support high temperatures or the system should exhibit a low power consumption, other methods have to be applied. To substantially decrease the sensor's time constants, the first-order time-derivative of the static signal can be calculated and used. This approach focuses on the change in signal during ad- and desorption phases and can be extracted from almost any sensor signal. It is discussed in more detail in section 4.3.

\subsubsection{Sensing mechanism}

A change in the sensor's resistance follows from a change in charge carrier concentration or mobility. The resistivity $\rho$ is proportional to the product of the charge carrier concentration and the mobility [36].

$$
\rho=\frac{1}{n e \mu_{e}+p e \mu_{h}}
$$

$e$ is the elementary charge, whereas $n$ and $p$, and $\mu_{e}$ and $\mu_{h}$ are the electron and carrier concentration, and mobility, respectively.

Adsorption of gas molecules on the graphene lattice can result in charge transfer, thus changing the sensor's resistivity. Moreover, the Fermi level $\mathrm{E}_{\mathrm{F}}$ is modified as well since the adsorbents act as chemical dopants [37]. Adsorption of electron-accepting molecules introduces extra holes, resulting in p-type doping, shifting the Fermi level down and increasing the resistivity for n-doped graphene, such as EG on SiC. Adsorption of electron-donating molecules, on the other hand, results in extra electrons, leading to n-type 


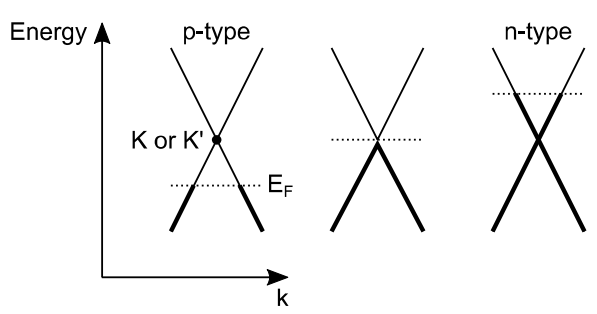

Figure 2.5: Schematic of Fermi-level dependence on doping in graphene. doping, shifting the Fermi level up and decreasing the resistivity. The effects of doping on the Fermi level are shown in Figure 2.5.

In free-standing graphene the Fermi level is located at the charge neutrality point, the Dirac point. In as-grown epitaxial graphene the Fermi level is shifted to $\approx 0.4 \mathrm{eV}$ above the Dirac point, due to the n-type doping from the buffer and substrate [38]. The sensing mechanism of graphene decorated with metal oxide NPs can be modeled by a receptor and a transducer process. Physisorption and chemisorption occurs at the metal oxide surface, forming the receptor process. The transport of electrons between metal oxide NPs and graphene as well as establishing the electrical signal belongs to the transducer process. [31]. It is believed that the change in resistivity is due to trapping of electrons by adsorbed gas molecules and additional scattering points induced by such. For example, adsorbed oxygen $\left(\mathrm{O}_{2}\right)$ on the sensing material withdraws electrons from the metal oxide NPs as shown in Equation (2.7).

$$
O_{2}+e^{-} \rightarrow O_{2}^{-} \text {(ads) }
$$

This negatively charged, adsorbed oxygen molecule causes a depletion region at the interface between the metal oxide NPs and the graphene lattice, leading to an decreased resistivity of the graphene lattice [31]. Reactions with oxidizing molecules will further increase the depletion region, whereas reactions with reducing molecules result in the trapped electrons being returned to the metal oxide NPs, thus increasing the resistivity of the graphene lattice again [39]. 


\section{Experimental Methods}

The research and development from ideation to realization of a novel sensing material involves several different fabrication and characterization techniques and systems. This chapter gives an overview of what is needed to end up with a functioning epitaxially grown and functionalized graphene gas sensor. It starts with the different deposition techniques and material characterization methods. Thereafter, the process of sensor fabrication itself is addressed and, finally, the gas mixing systems with utilized test gases are discussed.

\subsection{Deposition techniques}

Depending on the application in mind, several different deposition techniques may be used to grow a thin film on an already existing substrate. One distinguishes usually between physical vapor deposition (PVD) and chemical vapor deposition (CVD) techniques. In the case of CVD, a liquid or gaseous precursor undergoes a chemical change at a solid surface, resulting in the growth of a new solid film on top. PVD, on the other hand, uses thermal, mechanical or electromechanical processes to produce a thin solid film on top of a substrate. All techniques applied in this work belong to the family of PVD and are described in the following subchapters.

\subsubsection{Thermal evaporation}

Thermal evaporation is a very easy concept, where a target material, normally pure metals, gets evaporated using thermal energy and recondenses on a sample substrate mounted above it. A schematic of this process in shown in Figure 3.1. Small pieces of the target material are put into a metal 'boat' (holder), which is mounted below in parallel to the sample substrate. The heating occurs due to a high current of approximately several tens of amperes, 


\section{Experimental Methods}

which first melts the target metal and then slowly evaporates it. The evaporation rate is rather slow and depends on the supplied power and the material density. The deposited thickness is measured with a quartz crystal microbalance. This crystal is oscillating and changes its resonance frequency depending on its mass. With known evaporation material properties (density and Z-ratio) and the detected mass, the thickness of the deposited layer can be calculated. The Z-ratio describes the correction of the frequencychange-to-thickness transfer function for effects of acoustic-impedance mismatch between the deposited material and the crystal.

In this work, a custom built thermal evaporation chamber was used to deposit contacts titanium/gold ( $\mathrm{Ti} / \mathrm{Au}$ ) on top of some graphene sensors. The base pressure was $\sim 10^{-6}$ Torr before evaporation in a nitrogen background and the current was adjusted to obtain and keep a deposition rate of $\sim 0.1 \mathrm{~nm} / \mathrm{s}$. The Z-ratio for Ti is 0.628 and 0.381 for $\mathrm{Au}$.

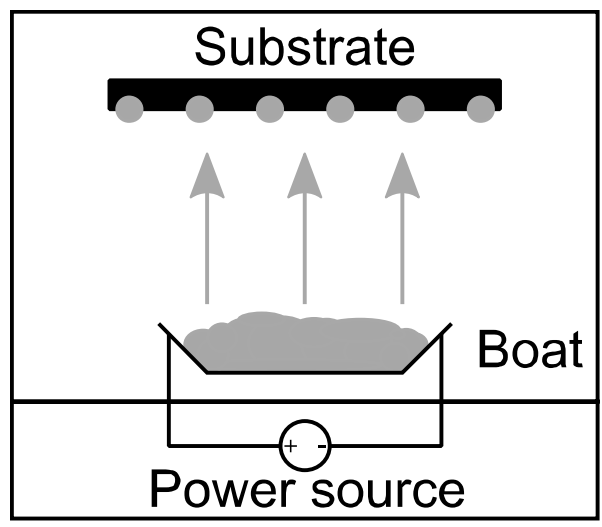

Figure 3.1: Schematic of thermal evaporation process. 


\subsubsection{Sputter deposition}

Sputter deposition techniques are usually divided into non-reactive and reactive sputtering. For non-reactive sputtering, the background ambient consists only of an inert gas like argon (Ar), whereas for the reactive sputtering a more reactive gas, e.g. oxygen, is present as well, which then can react with the ejected target atoms to form oxides. The main principle though is similar for both techniques: A sputter gas, normally argon, is ionized with a high energy source and directed to the so-called sputter target where it bombards the surface and ejects target atoms from the bulk [40]. Depending on the atomic weight of the sputter atom, the ejection mechanism differs. For the first mechanism, heavy sputter atoms hit the surface, transferring their energy into the surface, which generates a cascade of collision and eventually ejects atoms out of the surface. On the other hand, if a rather light atom hits the surface, it does not produce a cascade of collision. Instead, those ions get reflected from inside the surface layer, colliding with surface atoms from the backside and ejecting them. For argon with its intermediate mass, both mechanisms contribute to the sputter yield [41]. The sputter yield, defined as the ratio between ejected target atoms and incoming ions, is highly dependent on the angle, mass and kinetic energy of the incoming ion as well as the target material. These atoms move to the opposing substrate and grow into a film on it. Figure 3.2 shows a schematic of the general sputter process. Besides the ejection of target atoms, also secondary electrons are ejected. Accelerating these free electrons close to the target surface will further increase the rate of ionization, eventually leading to the forming of a plasma with its origin on the target surface. In this work, we use only "soft" deposition techniques with rather low kinetic energy of the incoming target atoms to maintain the integrity of the graphene surface and to not induce structural damage. 


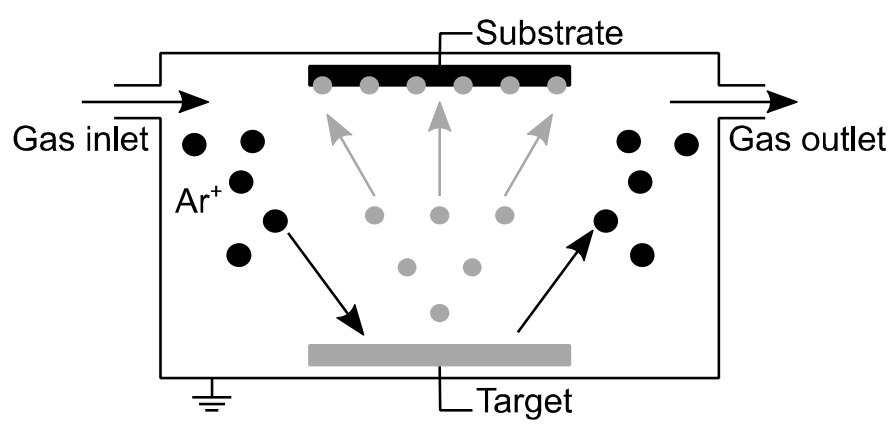

Figure 3.2: Schematic of sputter process.

\subsubsection{Magnetron sputtering}

As the name suggests, a magnet is utilized in a magnetron sputter system to confine the sputter electrons close to the target. The magnetic field bends the electrons' trajectory back to the target surface. This locally increases the plasma density through ionizing collisions with neutral atoms [42].

A custom built magnetron sputter system was used to deposit contacts (Ti/Au) on top of the sensor chips. For titanium, the base pressure was $1.5 \mathrm{~m}$ Torr with a voltage of $350 \mathrm{~V}$ and a current of $300 \mathrm{~mA}$, whereas the values were $1.9 \mathrm{mTorr}, 400 \mathrm{~V}$ and $200 \mathrm{~mA}$ for gold. Both depositions were performed with an argon flow of $25 \mathrm{ml} / \mathrm{min}$.

\subsubsection{Pulsed plasma hollow cathode sputtering}

A hollow cathode sputter system traps the electrons inside the cathode cylinder, where it is accelerated and repelled by the opposing cathode sheaths. This will lead to an oscillation of electrons inside the cathode and collisions of gas atoms with these highly energized electrons will form a plasma with a high degree of ionization. High power pulses are applied similar to high power impulse magnetron sputtering, which has been shown to enhance the ionization of the 
sputtered species substantially as compared to direct current magnetron sputtering. A schematic view of the experimental arrangement is given in Figure 3.3.

One of the main advantages of hollow cathode sputtering is the control of size, shape and dispersion of the deposited nanoparticles, as well as minimizing agglomeration on the substrate surface by alternating pulse amplitude, length and frequency [43], [44]. The nanoparticles are formed in the gas phase by the sputter vapor and their growth is depending on three main stages: In the first stage, a dimer is formed by nucleation during a three-body collision. This dimer then grows into a small cluster through the addition of more individual metal atoms/ions. If the cluster is large enough, it will get negatively charged in the second stage as the electron mobility will become higher as the mobility of positive ions. This leads to coagulation. When the coagulated cluster reaches sizes of $>10 \mathrm{~nm}$, the built-up negative charge prevents it from further coagulation. In the third stage, the particle grows only due to slow addition of metal atoms/ions [43].

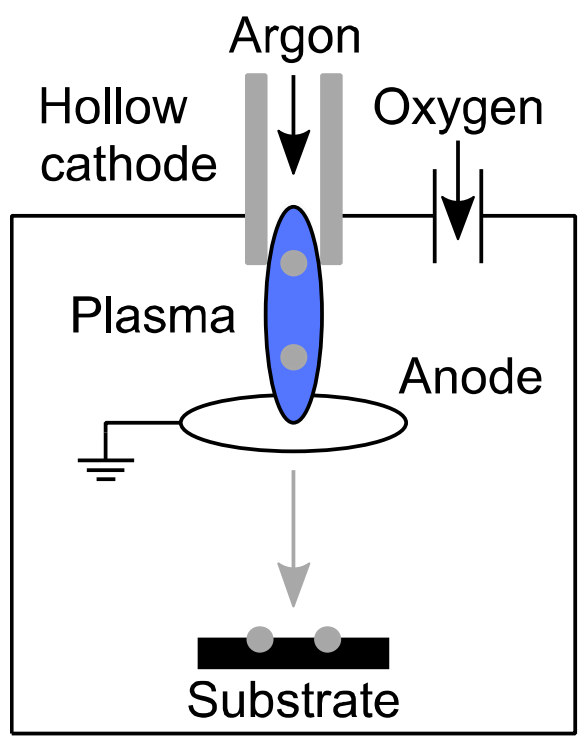

Figure 3.3: Schematic of hollow cathode sputter process based on [44]. 
Table 1: Used hollow cathode targets and their deposition parameters.

\begin{tabular}{l|cc}
$\begin{array}{l}\text { Sputter } \\
\text { material }\end{array}$ & $\begin{array}{c}\text { Deposition } \\
\text { time (min) }\end{array}$ & $\begin{array}{c}\text { Substrate } \\
\text { bias (V) }\end{array}$ \\
\hline $\mathrm{Fe}_{3} \mathrm{O}_{4}$ & 0.50 & floating \\
$\mathrm{Fe}_{3} \mathrm{O}_{4}$ & 1.00 & floating \\
$\mathrm{Fe}_{3} \mathrm{O}_{4}$ & 2.00 & floating \\
$\mathrm{Fe}_{3} \mathrm{O}_{4}$ & 4.00 & floating \\
$\mathrm{TiO}_{2}$ & 0.25 & +10
\end{tabular}

In this work, the technique has been leveraged for fabrication and deposition of metal oxide nanoparticles on graphene substrates. Titanium dioxide $\left(\mathrm{TiO}_{2}\right)$ and magnetite $\left(\mathrm{Fe}_{3} \mathrm{O}_{4}\right)$ nanoparticles were deposited on top of the graphene layer using this technique. The substrates were placed outside the dense plasma region, preventing energetic species from reaching them and damaging the graphene lattice. The discharge parameters for the $\mathrm{Fe}_{3} \mathrm{O}_{4}$ particles were: a pulse frequency of $1200 \mathrm{~Hz}$, a pulse width of $80 \mu$ s and an average power of $90 \mathrm{~W}$. A substrate bias ca be used to attract the particles to the substrate surface. For the $\mathrm{Fe}_{3} \mathrm{O}_{4}$ particles no bias was applied and the substrates were exposed to nanoparticle deposition ranging from 0.5 to 4 minutes. For the $\mathrm{TiO}_{2}$ nanoparticles the deposition time was $15 \mathrm{~s}$ and the bias was $+10 \mathrm{~V}$. Other process parameters are given in reference [44]. Important deposition parameters are summarized in Table 1.

\subsubsection{Pulsed Laser Deposition}

Pulsed laser deposition (PLD) uses a coupling of photonic energy to a bulk target material through electronic processes for growing a layer on a substrate opposite of the target. Both target and substrate are positioned within a vacuum chamber with an optical quartz glass window and usually with several in- and outlets for 
gases. A high energy laser pulse is focused onto the rotating target and is partially absorbed near the surface. Exceeding the ablation threshold of the target, a plasma plume occurs with particles moving perpendicular to the target. The material within the plasma plume can collide and react with background or inlet gases or ion sources. Nevertheless, it will recondense on the substrate, hence a layer will grow. A schematic of the general principle is shown in Figure 3.4.

The PLD process used in this work is described in [45]. Different target materials were ablated using a krypton fluoride $(\mathrm{KrF})$ excimer laser at a wavelength of $248 \mathrm{~nm}$. The oxygen partial pressure was kept at either 0.1 or 0.05 mbar. The laser pulses were adjusted to keep a layer thickness of around $0.5-1 \mathrm{~nm}$. The sensor substrates were kept at room temperature during deposition. Copper oxide $(\mathrm{CuO}), \mathrm{Fe}_{3} \mathrm{O}_{4}$, vanadium pentoxide $\left(\mathrm{V}_{2} \mathrm{O}_{5}\right)$ and zirconium dioxide $\left(\mathrm{ZrO}_{2}\right)$ have been used as target materials. Their process properties are summarized in Table 2. Unfortunately, the $\mathrm{ZrO}_{2}$ sample processed at 0.05 mbar was not available for measurements and $\mathrm{V}_{2} \mathrm{O}_{5}$ (0.1 mbar) physically broke after some measurements.

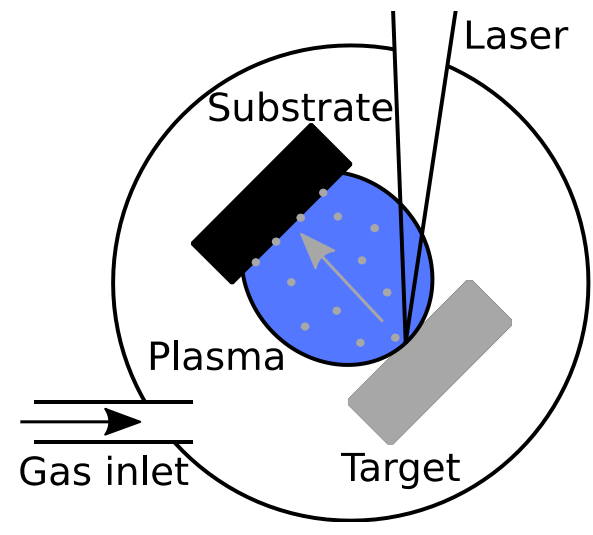

(a)

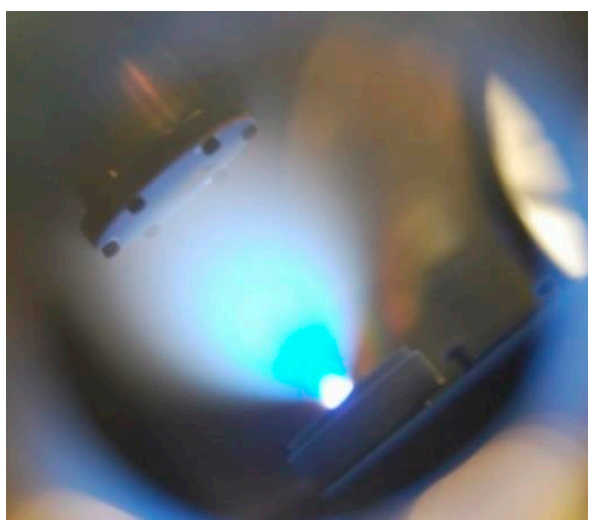

(b)

Figure 3.4: (a) Schematic of the PLD process and (b) picture of occurring plasma plume within the vacuum chamber of the PLD apparatus. Adapted from [46]. 
Table 2: Used PLD targets and their deposition parameters.

\begin{tabular}{l|ccc}
$\begin{array}{l}\mathrm{PLD} \\
\text { material }\end{array}$ & $\begin{array}{c}\mathrm{O}_{2} \text { pressure } \\
(\mathrm{mbar})\end{array}$ & $\begin{array}{c}\text { Laser fluence } \\
\left(\mathrm{J} / \mathrm{cm}^{2}\right)\end{array}$ & $\begin{array}{c}\text { Number of } \\
\text { laser pulses }\end{array}$ \\
\hline $\mathrm{CuO}$ & 0.05 & 5 & 120 \\
$\mathrm{CuO}$ & 0.10 & 5 & 180 \\
$\mathrm{Fe}_{3} \mathrm{O}_{4}$ & 0.05 & 7 & 150 \\
$\mathrm{Fe}_{3} \mathrm{O}_{4}$ & 0.10 & 7 & 200 \\
$\mathrm{~V}_{2} \mathrm{O}_{5}$ & 0.05 & 5 & 120 \\
$\mathrm{~V}_{2} \mathrm{O}_{5}$ & 0.10 & 3 & 200 \\
$\mathrm{ZrO}_{2}$ & 0.10 & 3 & 220
\end{tabular}

\subsection{Characterization methods}

To gain information about the cleanliness, thickness uniformity and induced damages of graphene samples, they are analyzed using atomic force microscopy (AFM), Raman spectroscopy and X-ray photoelectron spectroscopy (XPS) before and after the decoration with NPs or NLs. AFM gives information about the topography, while Raman spectroscopy and XPS is used to acquire information about structural properties. Additionally, XPS provides information about the chemical composition of the investigated material.

\subsubsection{Atomic Force Microscopy}

Using a very sharp needle attached to a cantilever, the AFM scans the surface of a specimen, where different scanning modes are possible: contact mode, non-contact mode and tapping mode. Here, only the tapping mode is used, where the needle oscillates close to its resonance frequency in z-direction while scanning the whole surface in a raster scan. Depending on the topology, van der Waals forces 
will change the oscillation amplitude of the cantilever, which is detected via a laser beam. Resolutions down to an atomic level can be achieved in height, which provides an opportunity to gain topography information of very flat samples such as graphene. In addition to the amplitude, also the phase difference between the excitation signal of the cantilever and its actual oscillation is recorded. The phase provides an insight into mechanical properties and the viscoelasticity of the studied material as it measures energy loss. For EG on $\mathrm{SiC}$, for example, it can reveal whether the surface consists of different graphene domains as different graphene thicknesses, monolayer, bilayer or multilayer exhibit different Young's moduli. Besides topography measurements, AFM measurements can also be adapted to measure, for example, the work function (Kelvin Probe Microscopy) or conductivity using a conductive tip.

In this work, a Quadrexed Dimension 3100 with a Nanoscope IVa controller was used with silicon tips (PPP-NCHR-50 from Nanosensors) with a tip radius of curvature below $7 \mathrm{~nm}$ exclusively in tapping mode. The overall roughness in height is calculated as the root mean square deviation.

$$
R_{q}=\sqrt{\frac{\sum_{i=1}^{N}\left(Z_{i}-Z_{\text {average }}\right)^{2}}{N}}
$$

$N$ is the total number of measurement points, $Z_{i}$ is the height at measurement point $i$ and $Z_{\text {average }}$ is the average height. Note that the roughness in height is calculated for an arbitrary area within the AFM measurement and should only be utilized to compare similar samples with each other.

\subsubsection{Raman spectroscopy}

With Raman spectroscopy, incoming monochromatic light gets scattered inelastically on the sample surface due to interactions with molecular vibrations or excitations. This inelastic scattering leads to a characteristic energy shift of the outgoing laser light, the so- 
called Raman effect. Raman scattering can be separated into Stoke scattering and Anti-Stoke scattering. The incident radiation has a higher frequency than the scattered radiation for Stoke scattering and vice versa for Anti-Stoke scattering [47]. Narrow optical filters shield the detector from reflected, non-scatted light from the laser.

The quality of graphene can easily be verified using Raman spectroscopy. A typical Raman spectrum of EG on $\mathrm{SiC}$ is shown in Figure 3.5. The important modes are D at $1350 \mathrm{~cm}^{-1}, \mathrm{G}$ at $1580 \mathrm{~cm}^{-1}, \mathrm{D}^{\prime}$ at $1610 \mathrm{~cm}^{-1}$ (not present here) and G' (also referred to as 2D) at $2700 \mathrm{~cm}^{-1}$. The $\mathrm{G}$ and $2 \mathrm{D}$ peaks refer to high quality graphene while the $\mathrm{D}$ peak arises only when disorder or lattice defects are present.

A micro Raman setup was used to perform Raman spectroscopy and reflectance measurements. A CCD (charge-coupled device) camera coupled to a monochromator (HR460) was utilized along with a $100 \times$ magnification objective which were excited at $532 \mathrm{~nm}$ using a solid-state laser. The power was kept at $17 \mathrm{~mW}$ for PEG and below $1 \mathrm{~mW}$ for DEG samples. The focused spot size had a diameter of $\sim 0.9 \mu \mathrm{m}$ on the sample and a system spectral resolution of approximately $5 \mathrm{~cm}^{-1}$ could be achieved. The Raman spectra of Si-face graphene were obtained by subtracting a reference Raman spectrum of $4 \mathrm{H}-\mathrm{SiC}$ (0001). A more detailed description of this setup can be found in [48].

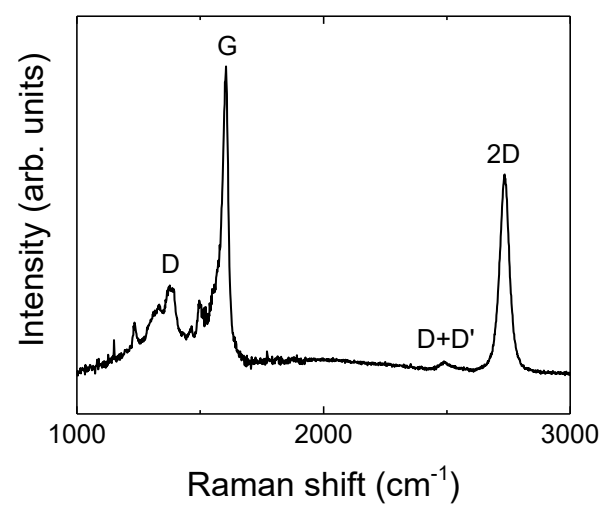

Figure 3.5: Typical Raman spectra of EG on $\mathrm{SiC}$ with important modes. Adapted from [Paper 1]. 


\subsubsection{X-ray photoelectron spectroscopy}

XPS is normally utilized to gain information about the surface chemistry of a sample, such as what elements are present and what other elements they are bonded to and the type of bonding. The typical depth that can be analyzed is around 0-20 $\mathrm{nm}$ and standard XPS setups are able to detect all elements with atomic numbers above 3 . The detection limits for most of the elements are in the parts per thousand range, but it is possible to achieve even ppm under special conditions. An XPS spectrum is the measurement of the kinetic energy and number of electrons that are released from the sample surface while being irradiated with an x-ray beam. To enable this detection, XPS measurements need to be performed in high vacuum $\left(<10^{-8} \mathrm{mbar}\right)$.

A Microlab 310-F spectrometer was used to investigate possible alterations to the graphene lattice made to the sample after the decoration with NPs and to establish if the NPs consisted of $\mathrm{Fe}_{3} \mathrm{O}_{4}$ as expected. More information about the system can be found in [49].

\subsubsection{Density functional theory}

Density function theory (DFT) is used to calculate and predict material behavior. It is based on quantum mechanical models which in turn are based on the Hohenberg-Kohn theorems [50]. DFT is often put to use in material science to investigate the electronic structure of many-body systems. Here, the adsorption of gas molecules on pristine EG (PEG) and decorated epitaxial graphene (DEG) with $\mathrm{Fe}_{3} \mathrm{O}_{4}$ NPs was investigated. The calculations are based on hybrid gas-phase DFT and executed with the Gaussian 16 Rev. B.01 program package [51]. PEG has been modeled as one $4 \times 5$ graphene layer on top of a $4 \times 5$ buffer layer, which is covalently bonded to the $4 \times 4$ Si-face surface of hexagonal $4 \mathrm{H}$-SiC. DEG was simulated by full geometrical optimization of $\mathrm{Fe}_{3} \mathrm{O}_{4}$ located on PEG, where all dangling bonds are passivated by hydrogen atoms. M06-2X level 
theory with consideration of a split basis set was used for all calculations [52]. The dispersion-corrected DFT functional M06-2X implicitly includes modified parameters associated with the HartreeFock exchange interaction, allowing the prediction of weak van der Waals interaction [53]. A LANL2DZ (Los Alamos National Laboratory 2 Double-Zeta) basis set was applied for iron (Fe) atoms and a 6-31G basis set for carbon, silicon, oxygen and hydrogen species [54]. All atoms were allowed to fully relax during geometrical optimization and no symmetry restrictions have been used. The adsorption energy of gas molecules ( $\left.E_{\text {ads }}\right)$ was calculated as

$$
E_{\mathrm{ads}}=\left(E_{\mathrm{tot}}^{\mathrm{PEG} / \mathrm{DEG}}+E_{\mathrm{tot}}^{\mathrm{gas}}\right)-E_{\mathrm{tot}}^{\mathrm{gas} @ \mathrm{PEG} / \mathrm{DEG}}
$$

$E_{\mathrm{tot}}^{\mathrm{PEG} / \mathrm{DEG}}$ and $E_{\text {tot }}^{\mathrm{gas}}$ are the total energies of isolated PEG or DEG templates and gas molecules, respectively. The total energy of PEG or DEG after the reaction with gas molecules is defined as $E_{\text {tot }}^{\text {gas@PEG/DEG }}$. A compensating correction for basis set superposition error (BSSE) was applied for a more accurate prediction of the adsorption energies [55].

\subsection{Sensor fabrication}

In this chapter, all the processes involved in the fabrication of the studied sensors are discussed. It starts with the growth of graphene on $\mathrm{SiC}$ chips and then elaborates how this chip is mounted to become a free-standing sensor unit and how the sensor readout is done.

\subsubsection{Graphene growth}

Since it was first experimentally produced in 2003, scientific advances and technology development in graphene have virtually exploded. As such, also the definition of graphene has been expanded to include materials that are not strictly only monoatomic carbon, but also including chemically reduced graphene oxide, composite 
materials comprising micrometer-sized graphene flakes, and multilayer graphene. Clearly, these different types of graphene will have different mechanical, optical, and electrical properties, where the choice of material should depend on the intended use of the graphene. The type of graphene depends on how it was synthesized, and there are many well-established methods for graphene growth [56]. The most common method for production of large area monolayer graphene relies on chemical vapor deposition, where a carbonrich precursor gas is used to grow graphene on a metallic catalyst substrate. This approach is highly scalable and can produce high quality graphene. However, the necessary transfer of the graphene to an insulating substrate - for electronic devices - ads an additional step which could lead to degradation or contamination of the graphene surface. Another, rather hands-on method is mechanical exfoliation. This method produces the highest quality graphene, but the process is very slow and not scalable. The method employed to grow graphene in this work was epitaxial growth of graphene through thermal decomposition of a $\mathrm{SiC}$ substrate. It is referred to as EG since the underlying Si-terminated $\mathrm{SiC}$ substrate on which the graphene is grown reconstructs and a supercell of the buffer layer matches quite well with the graphene lattice. Sublimation of silicon occurs at a much faster rate compared to carbon atoms in vacuum at elevated temperatures due to its higher vapor pressure. Usually, an overpressure of argon is applied to enhance the uniformity of the EG layer. Monocrystalline graphene can be grown over an entire wafer with very high quality on insulating or semi conducting SiC, thus allowing the direct fabrication of electronic devices. As mentioned in section 2.1.2, if $\mathrm{SiC}$ is heated to sufficiently high temperatures, Si-atoms sublimate and leave a carbon-rich layer behind which eventually forms graphene. Figure 3.6 shows a simplified growth process. 


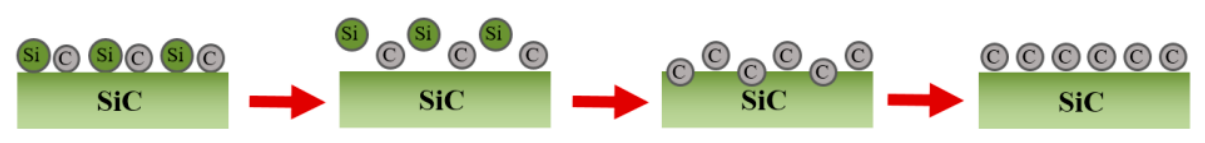

Figure 3.6: Schematic of EG growth on SiC.

In this work, growth was performed on hexagonal polytype $4 \mathrm{H}-\mathrm{SiC}$ (0001) on-axis Si-terminated substrates. SiC is with a bandgap of $3.26 \mathrm{eV}$ a wide bandgap semiconductor that is either semiconducting or semi-insulating depending on the doping. Its crystal structure matches with the graphene lattice. Moreover, it is available for purchase in very high quality on wafer scale. For the samples in this study, semi-insulating $\mathrm{SiC}$ was used. EG was prepared by sublimation of $\mathrm{SiC}$ and subsequent graphene formation at $2000^{\circ} \mathrm{C}$ in argon and at a pressure of 1 bar [57]. The graphene layer forms on top of a monoatomic carbon buffer layer, which is still covalently bonded to the $\mathrm{SiC}$ substrate. As a result, and sensor basis, EG with a monolayer ratio of about $98 \%$ (2 \% bilayer) was achieved.

\subsubsection{Sensor mounting}

The EG-on-SiC-chip is $7 \times 7 \mathrm{~mm}$ big and needs to be diced before further processing. To cut the chips, a $30 \mu \mathrm{m}$ thin diamond blade is used with an automatic dicing saw (DISCO DAD321, Japan) and deionized water cooling during the cutting process. The resulting cut has a width of about $50 \mu \mathrm{m}$. To ensure no contamination is induced to the graphene surface, a protective layer of positive photoresist (SU1818) is applied beforehand. The photoresist is applied via spin coating for $30 \mathrm{~s}$ at $4000 \mathrm{rpm}$ with an acceleration speed of $2000 \mathrm{rpm} / \mathrm{s}$. The sample is then baked at $100{ }^{\circ} \mathrm{C}$ for $20 \mathrm{~min}$ in an oven in ambient air for curing. The backside of the fully transparent chips is marked with a diamond pen to exclude using the wrong side. To remove the photoresist after cutting, the chip is put into pure acetone, then into pure ethanol and then blow-dried using a 
nitrogen gun. The samples were either halves or quarters of the initial chip. After successful growth and dicing of the chips, the high quality of the graphene surface is verified. As a first step of transforming the graphene chip into a graphene gas sensor, electrodes are deposited on top. The contacts have either been deposited through thermal evaporation or sputtering of titanium $(2 \mathrm{~nm})$ and gold $(200 \mathrm{~nm})$ sequentially. The arrangement of electrodes varies, thus influencing the baseline resistance measured in-between two electrodes. In this work, all NP DEG samples had four $0.5 \mathrm{~mm}$ squared contacts with a $1 \mathrm{~mm}$ gap in between and all NL DEG samples had two $2 \mathrm{~mm}$ squared contacts with a $1 \mathrm{~mm}$ gap. To enable a closed loop temperature control, each sensor chip is glued using Aremco Ceramabond 571 on top of a ceramic heater substrate (Heraeus GmbH, Germany) with an additional Pt-100 temperature sensor (Heraeus GmbH, Germany). This device was mounted on top of a TO8-socket and connected to its pins using gold-wire bonding and silver glue (Epotek E3081). This setup limits the working temperature to $300{ }^{\circ} \mathrm{C}$, but measurements were only performed up to $200{ }^{\circ} \mathrm{C}$ as a safety measure. Figure 3.7 shows a mounted sensor with all necessary parts.

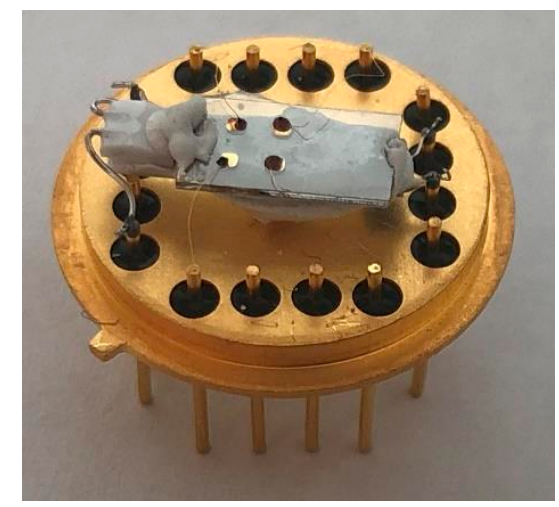

Figure 3.7: Photograph of mounted sensor device. Here $\mathrm{Fe}_{3} \mathrm{O}_{4}$ NP DEG. 


\subsubsection{Data acquisition}

The resistance of the graphene layer in-between the deposited contacts is measured over time and used as the sensor signal. As mentioned in section 2.2.2, the charge carrier density will change due to gas interaction, thus altering the sensor's resistance. A schematic of this is shown in Figure 3.8. The resistance is measured with a Sourcemeter (Keithley 2601, USA) and transferred to a custommade computer program with a sampling rate of $1 \mathrm{~Hz}$. If not specified otherwise, the resistance was calculated from the current measured at $3 \mathrm{~V}$. Some measurements were performed using a specialized board from 3S GmbH, Saarbrücken, Germany, instead. The measurement voltage were kept the same. More information about this system can be found in [58]. A special temperature controller was used to monitor and adjust the sensor temperature. The controller can be programmed to keep the sensor at a given temperature or change it over time to create ramps or plateaus. The ceramic heater heats the sensor and the Pt-100 reads back the actual temperature.

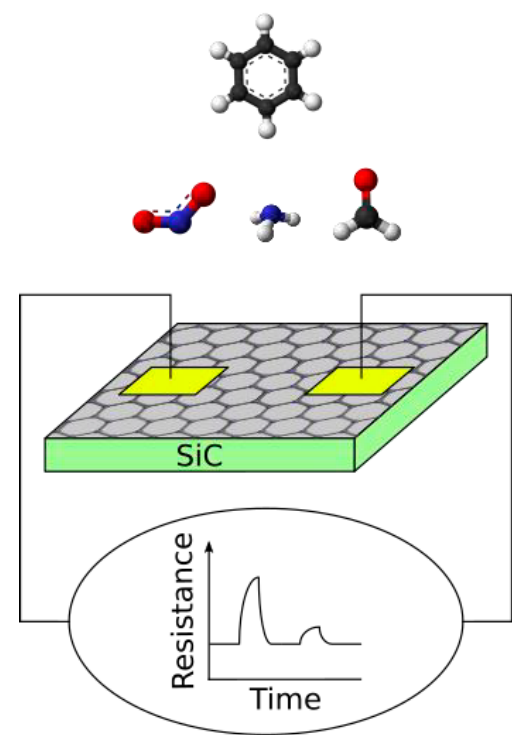

Figure 3.8: Schematic of graphene sensor readout. 


\subsection{Gas mixing apparatus}

To perform gas measurements with well-defined total gas flow and concentrations over the sensor, a gas mixing apparatus (GMA) was used. The GMA can provide different gases whose flows are regulated by mass flow controllers (MFCs). A known gas mixture, usually from a gas cylinder, is connected with a high pressure to the MFCs. Each mass flow controller has a fixed maximum flow of which a range between 5 and $100 \%$ can be reliably set. Zero air out of a zero air generator or pure nitrogen $\left(\mathrm{N}_{2}\right)$ can be used with the possibility of varying humidity and oxygen partial pressure as the background or carrier gas for the applied gases. The humidity is produced by splitting the dry carrier gas into two streams, one of which goes through a water bottle, the so-called "bubbler", which can be assumed having $100 \%$ relative humidity (RH). After this, both streams are reassembled. Humidity can be adjusted by varying the split ratio through MFCs. To ensure that no humidity could leak into the system when performing measurements under dry conditions, the bubbler line was disconnected for those measurements. If not especially mentioned, a total flow of $100 \mathrm{ml} / \mathrm{min}$ was applied for all experiments. Test gases are provided via a gas bottle, where the

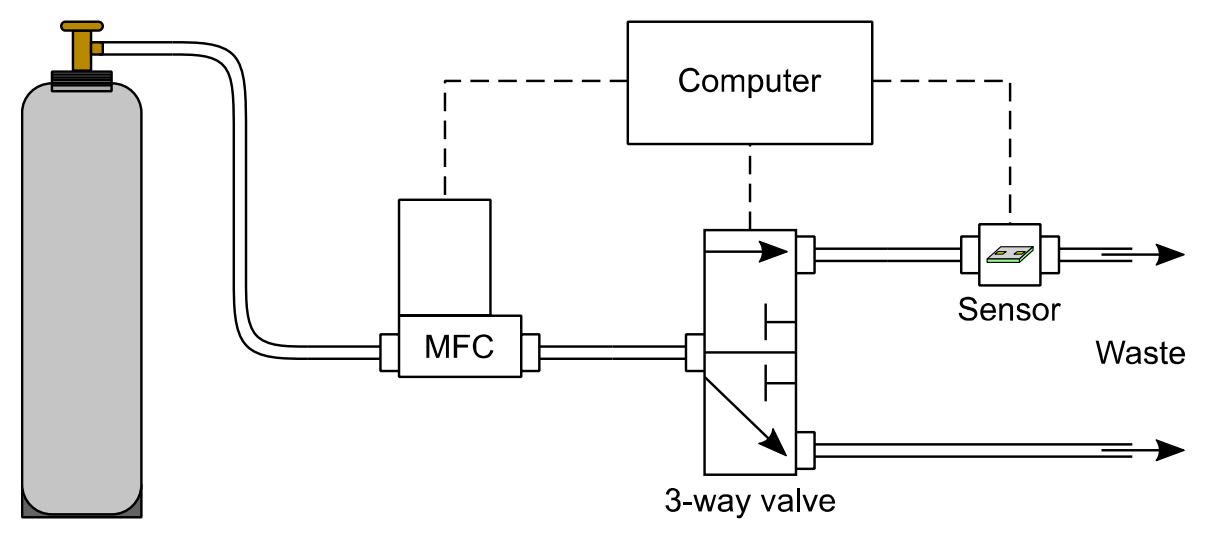

Figure 3.9: Schematic of gas mixing apparatus. 


\section{Experimental Methods}

test gas is diluted to a specific concentration in the same carrier gas used as background gas, or via a permeation oven. The purity of the test gases is N5.0, which means $99.999 \%$ purity. The sensors are inserted in a flow chamber with a volume of $3 \mathrm{ml}$. Using specially designed flow chambers, either one sensor, two sensors, or one sensor with a UV-LED (light emitting diode) on the opposite side can be used during a measurement. Figure 3.9 gives an overview of how such a system can look like.

For all measurements performed in Linköping, the carrier gas for the test gas bottles was pure nitrogen. The background and purging gas was applied through two MFCs giving a mixture of $80 \%$ nitrogen and $20 \%$ oxygen. The test gas was added through an additional MFC into the same line. In total, four different test gases can be applied during a single measurement session. The whole gas flow enters a four-way valve which can direct the gas flow either through the sensor chamber or directly to waste. To maintain a constant flow and atmosphere, a second branch with only two MFCs, nitrogen and oxygen, is connected to the four-way valve. When the valve switches one gas flow to waste, the other is automatically lead through the sensor chamber. This system enables sharp steps and time for a new gas mixture to settle. The system is equipped with MFCs from Bronkhorst High-Tech B.V., AK Ruurlo, Netherlands, with maximum flow rates of 20,50 or $100 \mathrm{ml} / \mathrm{min}$. Nitrogen MFCs had a maximum flow of $100 \mathrm{ml} / \mathrm{min}$ whereas all other MFCs had $50 \mathrm{ml} / \mathrm{min}$ except for the $\mathrm{NH}_{3} \mathrm{MFC}$ with $20 \mathrm{ml} / \mathrm{min}$. A more detailed description of the system can be found in [59].

Measurements performed in Saarbrücken used zero-air generated by a GT Plus ultra-zero air generator (VICI AG International, Schenkon, Switzerland) as background gas instead. To enable measurements with lower concentrations than what is possible with the standard procedure of injecting the test gas with one MFC, an additional flow line can be connected the predilute the gas. In this case, two additional MFCs $(500 \mathrm{ml} / \mathrm{min}$ for carrier gas and 10 or $20 \mathrm{ml} / \mathrm{min}$ for test gas) are added to predilute the test gas before 
the new gas flow is injected into the main gas stream. With this procedure, a dynamic dilution over more than four orders of magnitude can be achieved [60]. This allows the dilution of $100 \mathrm{ppm}$ gas bottles down to one-digit ppb concentrations over the sensor. Another option to prepare rather low concentrations in the gas flow is a permeation oven. Here, a permeation tube is placed in a heated and sealed oven chamber. The permeation tube contains the pure test substance which slowly diffuses through the tube walls made of perfluoroalkoxy alkane (PFA). The rate of diffusion is highly dependent on the oven temperature which therefore is kept constant. The outflow is connected to the main gas flow via an MFC so that the permeation oven is conceptually similar to a gas bottle with a variable test gas concentration. Permeation tubes do not only enable low concentrations, but can also be used for gases with very high vapor pressure, which cannot be kept in gaseous form in pressurized gas bottles. More details about the system can be found in [61], [62].

If UV irradiation is desired during a measurement, a special sensor chamber is used where the UV-LED can be placed opposite of the sensor within the sensor chamber. Two different LEDs with wavelengths of $265 \mathrm{~nm}$ (Sensor Electronic Technology Inc, S-T39BF1-265-01-1-050) and $355 \mathrm{~nm}$ (Roithner Lasertechnik GmbH, XSL355-3E-R6) have been put to use.

\subsubsection{Test gases}

All used test gases are shortly defined and characterized through their chemical composition, appearance and pollutant guidelines. The World Health Organization [63] as well as the European Parliament [64] have guidelines for pollutant acceptance levels for indoor-air quality and these references are used if not specified otherwise.

Ammonia $\left(\mathrm{NH}_{3}\right)$ is a very toxic gas at higher ppm concentrations. Nevertheless, it is one of the most produced inorganic chemicals with a wide use in the production of pharmaceuticals, explosives, 


\section{Experimental Methods}

cleaning products and as a precursor for fertilizers, with the latter alone being responsible for $80 \%$ of the total $\mathrm{NH}_{3}$ production [65]. Moreover, $\mathrm{NH}_{3}$ can be related to the formation of secondary particulate matter by reacting with acidic species, like $\mathrm{NO}_{\mathrm{x}}$ or sulfur dioxide $\left(\mathrm{SO}_{2}\right)$, to form ammonium-containing aerosols, which constitute the major fraction of $\mathrm{PM}_{2.5}$ aerosols in the atmosphere [66].

Nitrogen dioxide $\left(\mathrm{NO}_{2}\right)$ can cause respiratory symptoms and has an acceptance level of $100 \mathrm{ppb}$ annual average and $20 \mathrm{ppb}$ for one hour exposure. It is mostly produced through internal combustion engine sources accountable for around $40.5 \%$ of $\mathrm{NO}_{\mathrm{x}}$ emissions in Europe, followed by energy production (22.5\%) [67].

Volatile organic compounds (VOCs) have unfortunately no universal definition. They are defined via the boiling points [68] over vapor pressures [69] of the molecules, or their participation in atmospheric photochemical reactions [70]. Although some of them are hazardous to humans even at very low concentrations, they are widely put to use in industry and everyday products as solvents. In this work, benzene and formaldehyde are used as model VOCs.

Benzene $\left(\mathrm{C}_{6} \mathrm{H}_{6}\right)$ is a genotoxic aromatic compound, especially associated with leukemia, and has therefore very low acceptance levels. At the time of writing, France has with $0.6 \mathrm{ppb}$ the lowest acceptance level [71]. According to the latest published WHO recommendations, however, there is no safe level for benzene. It is mostly produced as a byproduct of traffic and is, additionally, often used as a component of solvents in cleaning agents or paint [72].

Formaldehyde $\left(\mathrm{CH}_{2} \mathrm{O}\right)$ has an acceptance level of $80 \mathrm{ppb}$ and is genotoxic. In low concentrations, $\mathrm{CH}_{2} \mathrm{O}$ usually does not pass beyond the respiratory system which limits direct cause to portal-ofentry effects like nasal cancer and sensory irritation. It emerges from combustion processes and is often used in its aqueous solution as disinfectant or conservative in everyday products as well as in the production of plastics [73].

All gases come with a purity level of 5.0 except nitrogen, which is generated from a liquid source and has a purity of 6.0 in gaseous 
form. Table 3 gives an overview of the gases and their specifications for measurements performed in Linköping and Saarbrücken, respectively.

Table 3: Used test gases and their system properties.

\begin{tabular}{l|cc} 
Test gas & $\begin{array}{c}\text { Linköping } \\
\text { Bottle concentra- } \\
\text { tion (ppm) }\end{array}$ & $\begin{array}{c}\text { Saarbrücken } \\
\text { Bottle concentra- } \\
\text { tion (ppm) }\end{array}$ \\
\hline 0-air ${ }^{2}$ & $/$ & $100 \%$ \\
Nitrogen & $100 \% 3$ & $100 \%$ \\
Oxygen & $100 \%$ & $/$ \\
Ammonia & 2,500 & $/$ \\
Benzene & 0.5 & $0.1^{4}, 100$ \\
Formaldehyde & 4 & 57 \\
Nitrogen dioxide & 1 & $10^{5}$
\end{tabular}

20 -air is generated using a GT Plus ultra-zero air generator (VICI AG International, Schenkon, Switzerland) and is not retrieved from a gas bottle. ${ }^{3}$ Nitrogen is generated from a liquid source and is not retrieved from a gas bottle.

${ }^{4} 0.1 \mathrm{ppm}$ source concentration from permeation tube at $80^{\circ} \mathrm{C}$.

${ }^{5}$ Nitrogen dioxide used in Saarbrücken had air as bottle carrier gas. 



\section{Results and Discussion}

This chapter presents and discusses the experimental results of the work. The first section describes integrity studies performed on the graphene samples before and after functionalization. Then the gas measurements of the different sensors with different gases and environmental influences are discussed. The last section deals with special data treatment to further improve the sensing properties.

\subsection{Layer characterization}

Before using a graphene chip for the production of a sensor device, its topography and structural integrity is analyzed. This step is repeated after the surface decoration.

\subsubsection{Topography}

To make sure that graphene formed a continuous layer and was free from contamination, the topography was measured using AFM. A typical topography of the grown pristine graphene layer is shown in Figure 4.1 (a). The steps from the SiC step bunching that occurs during the high temperature growth have a height of typically 0.5-1.5 nm and form terraces. The low height difference can be seen in the inset of Figure 4.1 (a), which shows the horizontal height profile for a $2 \mathrm{~mm}$ line scan. The surface roughness $R_{q}$ within such a terrace is with $0.25 \mathrm{~nm}$ very small. The corresponding phase image (Figure 4.1 (b)) shows a very continuous value with the only exceptions being the step edges and a bi- or multilayer graphene patch in the lower left corner. This is an additional indicator for a high quality monolayer graphene lattice. Figure 4.1 (c) shows the C terminated backside surface of such a chip. It is still very flat, but shows a completely different crystalline structure pattern with presumably several layers of graphene grown on it. 


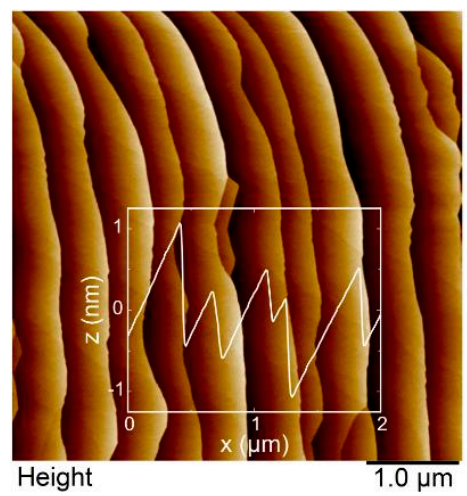

(a)

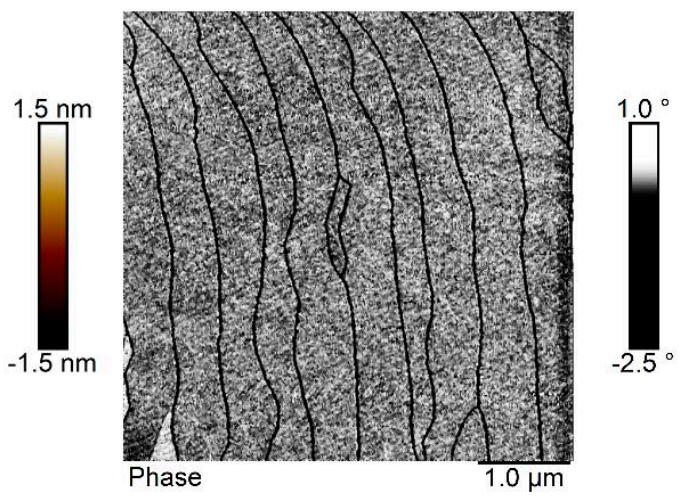

(b)

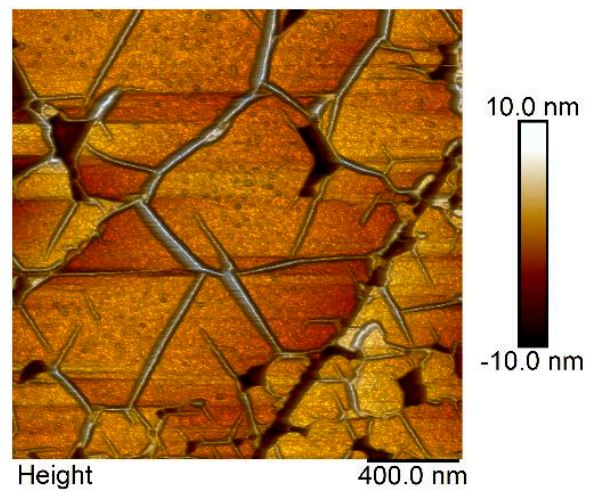

(c)

Figure 4.1: AFM images of (a) pristine graphene on Si-terminated 4H$\mathrm{SiC}$ with height profile as inset, (b) its corresponding phase image and (c) backside (C-face) of SiC chip.

Furthermore, the samples were analyzed again after surface decoration. Figure 4.2 (a) shows the AFM image in of the $\mathrm{Fe}_{3} \mathrm{O}_{4}(0.1)$ NL DEG (see section 3.1.3) sample. The surface does not differ much from the pristine sample, as a very thin $(\sim 0.5-1 \mathrm{~nm})$ continuous layer is deposited onto the graphene surface. The dominating features are still the step edges formed by the SiC chip. 


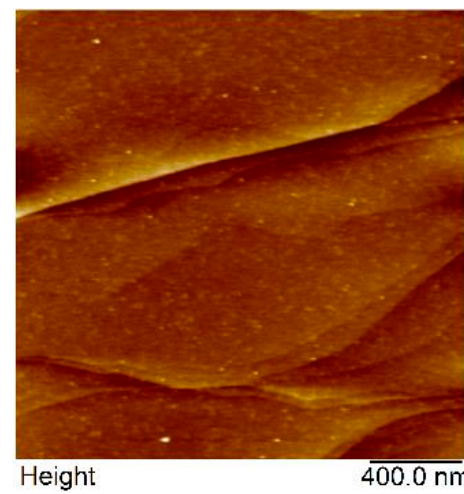

(a)

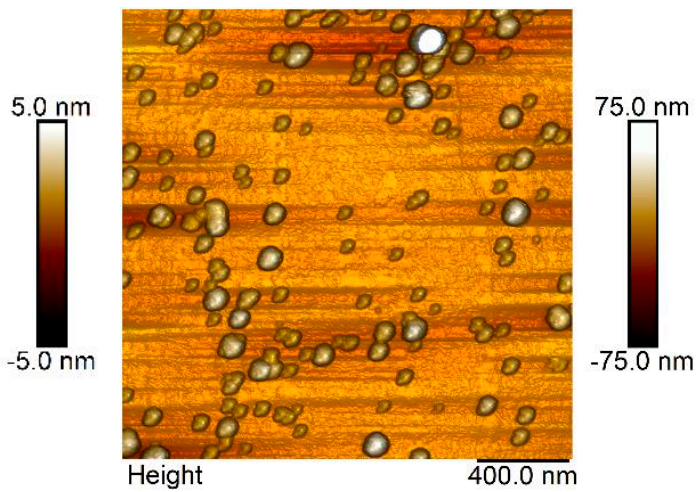

(b)

Figure 4.2: (a) AFM image of $\mathrm{FE}_{3} \mathrm{O}_{4} \mathrm{NL}$ (a) and $\mathrm{NP}$ (b) DEG sample.

After the decoration with $\mathrm{Fe}_{3} \mathrm{O}_{4} \mathrm{NPs}$, the graphene surface looks completely different (Figure 4.2 (b), here 0.5 min deposition time). The NPs are now dominating the surface roughness and the steplike plateaus with their small differences in height can hardly be resolved at the Z-scale needed to show all features of the NPs. The particle coverages and average particle diameters of the NP DEG samples investigated in this work are summarized in Table 4 . The particle size, was calculated after evaluating 100 single particles and agglomerates per sample. For the $\mathrm{Fe}_{3} \mathrm{O}_{4}$ samples with different deposition times, the particle size should stay approximately constant, as no other deposition parameters have been modified. This is true to a large extent for single particles, but with a longer deposition time, more agglomerates are formed. An exemplary histogram of the particle size distribution is discussed in [Paper 2]. The particle size can have an impact on the sensor's sensitivity and selectivity and thus is another parameter that can be optimized for sensors performance tuning [6]. This was, however, not investigated in this work. With an increase in deposition time, the coverage should increase. As the sample deposited for 2 min exhibits a larger coverage than the one with 4 min deposition time (compare Table 4), it is believed, that they have been wrongly labelled during 
Table 4: Resulting coverages and particle sizes after the decoration with NPs.

\begin{tabular}{l|ccc}
$\begin{array}{l}\text { Sputter } \\
\text { material }\end{array}$ & $\begin{array}{c}\text { Deposition } \\
\text { time (min) }\end{array}$ & $\begin{array}{c}\text { Avg. particle } \\
\text { size (nm) }\end{array}$ & $\begin{array}{c}\text { Coverage } \\
(\%)\end{array}$ \\
\hline $\mathrm{Fe}_{3} \mathrm{O}_{4}$ & 0.50 & $80 \pm 10$ & $15 \pm 5$ \\
$\mathrm{Fe}_{3} \mathrm{O}_{4}$ & 1.00 & $80 \pm 10$ & $25 \pm 5$ \\
$\mathrm{Fe}_{3} \mathrm{O}_{4}$ & 2.00 & $80 \pm 10$ & $55 \pm 5$ \\
$\mathrm{Fe}_{3} \mathrm{O}_{4}$ & 4.00 & $80 \pm 10$ & $45 \pm 5$ \\
$\mathrm{TiO}_{2}$ & 0.25 & $90 \pm 10$ & $15 \pm 5$
\end{tabular}

the decoration step as otherwise the correlation between deposition time and coverage follows the expected trend. Regarding AFM images, all graphene samples are very clean, except for the deposited functionalization material.

\subsubsection{Structural integrity}

Raman measurements were performed to verify that the integrity of the graphene layer is still ensured even after the decoration with NPs or NLs. The comparison between PEG, $\mathrm{Fe}_{3} \mathrm{O}_{4}$ NP DEG and $\mathrm{Fe}_{3} \mathrm{O}_{4}(0.1)$ NL DEG is shown in Figure 4.3. For a better comparison, all spectra were normalized to the $\mathrm{G}$ peak. This is possible because the $\mathrm{y}$-axis is in arbitrary units. The lower line belongs to the PEG reference which shows the $\mathrm{G}$ and $2 \mathrm{D}$ peaks, typical for sp2 hybridized carbon, around $1610 \mathrm{~cm}^{-1}$ and $2737 \mathrm{~cm}^{-1}$, respectively [74]. The rather small full width at half maximum (FWHM) value of $35 \mathrm{~cm}^{-1}$ at the $2 \mathrm{D}$ peak is indicative of uniform monolayer graphene within the irradiated spot [75]. The features above $1280 \mathrm{~cm}^{-1}$ and extending into the $\mathrm{G}$ peak are related to the interfacial buffer layer between the graphene and the $\mathrm{SiC}$ substrate [74]. Although they overlap with the position of the D peak at $1350 \mathrm{~cm}^{-1}$, they are not related to defects. If damage is induced into the graphene lattice, the 
D peak would rise. It can be clearly seen that the spectra after decoration are almost the same as the reference, indicating that no damage was introduced. The position of the $2 \mathrm{D}$ peak is the same for all samples, but the $\mathrm{G}$ peak ( $1605 \mathrm{~cm}^{-1}$ for PEG) varies slightly with $\pm 10 \mathrm{~cm}^{-1}$. This is most likely be due to different levels of strain in the graphene lattices [76] or possibly a result of different doping in the graphene due to charge transfer between graphene and decoration material. Moreover, the 2D peak broadens for the NL DEG sample which could be related the inclusion of bi- or multilayer graphene in the measured spot. Also the lower G/2D peak ratio is another indication for this.

If the ambient pressure is decreased during the PLD deposition, damage starts to be induced into the graphene lattice. Figure 4.4 shows such a case where $\mathrm{Fe}_{3} \mathrm{O}_{4} \mathrm{NL}$ was deposited using 0.05 mbar, introducing slight damage to the graphene lattice. This is due to an increase in disorder and impurities, which can be seen as an increase in the $\mathrm{D}$ peak around $1350 \mathrm{~cm}^{-1}$. Similarly, damage is also induced if too many nanoparticles are deposited on top of the graphene lattice. Here, $\mathrm{TiO}_{2}$ was deposited until it reached a covered almost the whole surface. The height of the D peak strongly increased and even surpasses the G peak.

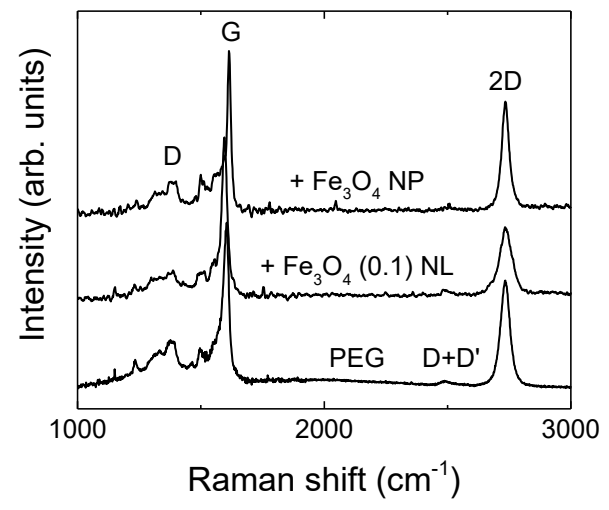

Figure 4.3: Raman spectra of PEG, $\mathrm{Fe}_{3} \mathrm{O}_{4}(0.1) \mathrm{NL}$ DEG and $\mathrm{Fe}_{3} \mathrm{O}_{4} \mathrm{NP}$ DEG. Adapted from [Paper 1]. 


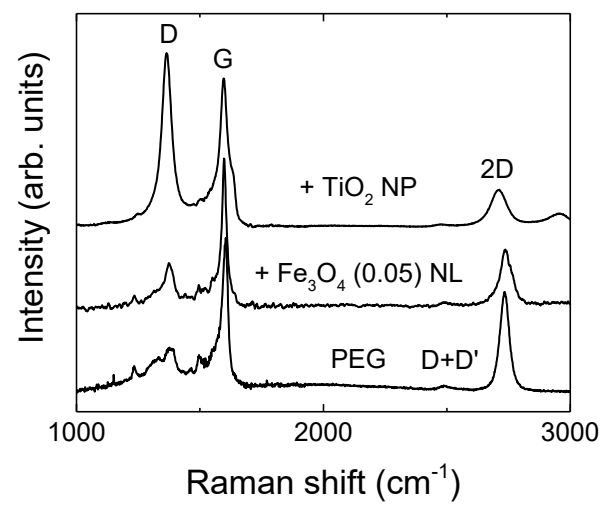

Figure 4.4: Raman spectra of $\mathrm{PEG}$, and $\mathrm{Fe}_{3} \mathrm{O}_{4} \mathrm{NP}$ DEG and $\mathrm{Fe}_{3} \mathrm{O}_{4}(0.05)$ NL DEG.

\subsubsection{Chemical composition}

The integrity of the graphene lattice after surface decoration was already verified using Raman spectroscopy. Additionally, XPS measurements were performed to support the assumption of integrity and to gain information about the chemical composition of the sensor surface. This measurement was only performed with one graphene sample before and after the decoration with $\mathrm{Fe}_{3} \mathrm{O}_{4} \mathrm{NPs}$. Figure 4.5 shows the Fe2p and O1s core level spectra for PEG and $\mathrm{Fe}_{3} \mathrm{O}_{4}$ NP DEG. The Fe2p peak and the O1s peak should be at binding energies of about 711 and $532 \mathrm{eV}$ [77]. The quantification of oxygen based on the XPS core level spectrum shows a five times higher oxygen concentration for $\mathrm{Fe}_{3} \mathrm{O}_{4} \mathrm{NP}$ DEG compared to PEG. This strong difference, with an additional peak appearing at $530 \mathrm{eV}$, is in good agreement with the presence of $\mathrm{Fe}-\mathrm{O}$ in the $\mathrm{Fe}_{3} \mathrm{O}_{4}$ NPs. Moreover, two peaks at 710.9 and $724.4 \mathrm{eV}$ strongly suggest the presence of iron species, which cannot be seen before the decoration. These measurements support the assumption of a soft and clean NP deposition on top of the graphene lattice. 


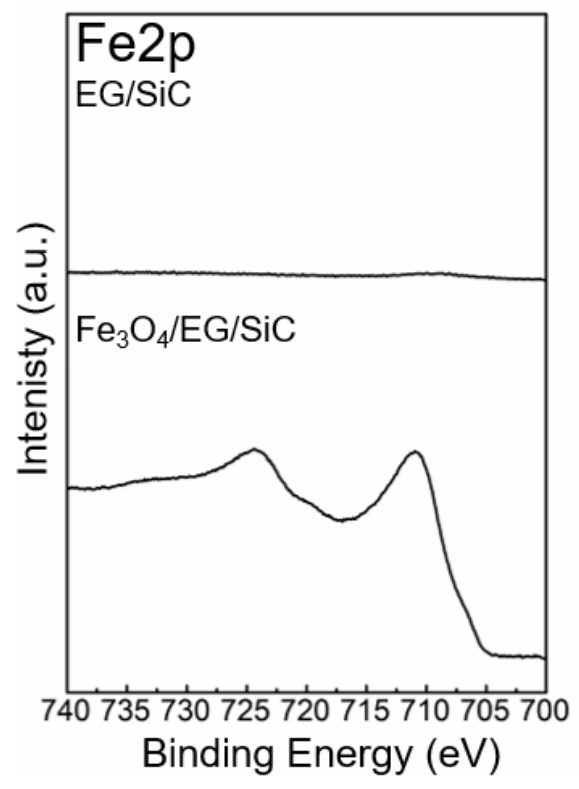

(a)

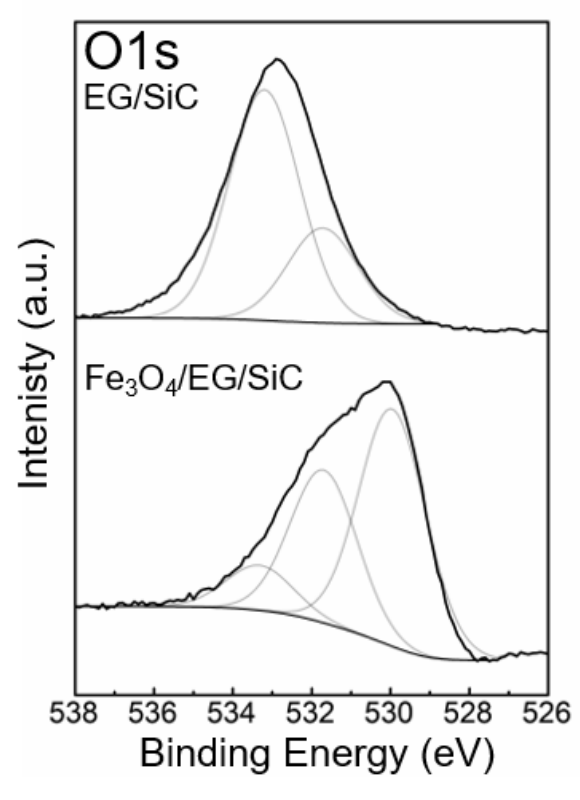

(b)

Figure 4.5: (a) O1s and (b) Fe2p XPS core level spectra for PEG (top) and $\mathrm{Fe}_{3} \mathrm{O}_{4}$ NP DEG (low) [Paper 2].

\subsubsection{Theoretical considerations}

DFT calculations have been performed to investigate the different adsorption energies between $\mathrm{C}_{6} \mathrm{H}_{6}$ and $\mathrm{CH}_{2} \mathrm{O}$, and $\mathrm{PEG}$ and $\mathrm{Fe}_{3} \mathrm{O}_{4}$ NP DEG, respectively, to theoretically verify that the NP decoration would increase the gas sensitivity. Figure 4.6 shows the energetically favored adsorption configurations of the gas molecules on PEG and DEG. The adsorption energy for $\mathrm{C}_{6} \mathrm{H}_{6}$ on DEG is $E_{\text {ads }}=1.795 \mathrm{eV}$, whereas the adsorption energy on PEG is with $E_{\text {ads }}=0.284 \mathrm{eV}$ significantly lower. In the absence of the $\mathrm{Fe}_{3} \mathrm{O}_{4} \mathrm{NPs}$, the $\mathrm{C}_{6} \mathrm{H}_{6}$ molecule adsorbs parallel to the surface in the flat geometry. In this case, the center of $\mathrm{C}_{6} \mathrm{H}_{6}$ ring lays on top of a carbon atom 
belonging to the graphene. With $\mathrm{Fe}_{3} \mathrm{O}_{4} \mathrm{NPs}$ being present, the formation of a strong chemical bond between the $\mathrm{C}_{6} \mathrm{H}_{6}$ ring and one of the $\mathrm{Fe}$ atoms, leading to a tilted $\mathrm{C}_{6} \mathrm{H}_{6}$ adsorption, is facilitated.

The $\mathrm{CH}_{2} \mathrm{O}$ molecule behaves similarly with adsorption energies of $0.149 \mathrm{eV}$ and $1.870 \mathrm{eV}$ for the adsorption on PEG and DEG, respectively. In conclusion, weak physisorption of $\mathrm{C}_{6} \mathrm{H}_{6}$ and $\mathrm{CH}_{2} \mathrm{O}$ on PEG can be altered to strong chemisorption with the presence of $\mathrm{Fe}_{3} \mathrm{O}_{4}$ NPs. To conclude, $\mathrm{Fe}_{3} \mathrm{O}_{4}$ DEG graphene should exhibit an enhanced response towards the exposure of $\mathrm{C}_{6} \mathrm{H}_{6}$ and $\mathrm{CH}_{2} \mathrm{O}$, with a slightly higher estimated interaction with $\mathrm{CH}_{2} \mathrm{O}$.

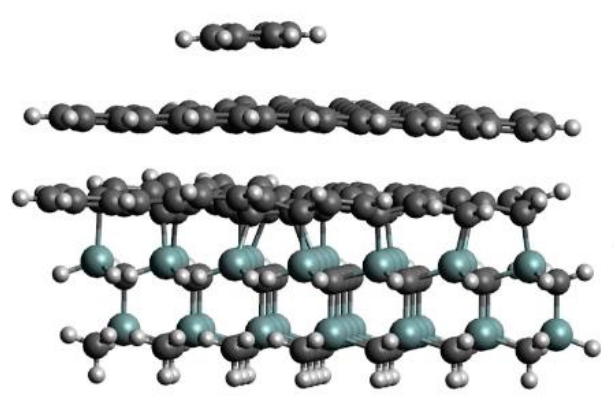

(a)

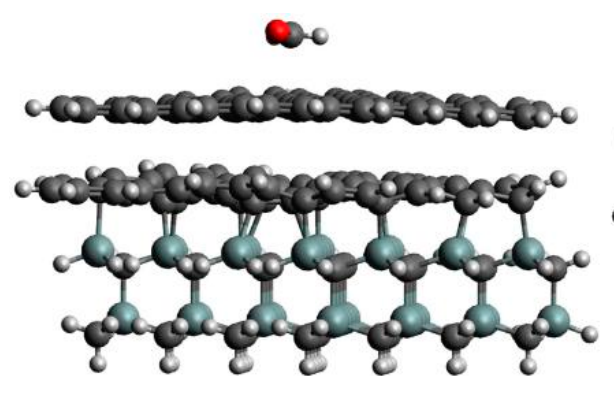

(c)

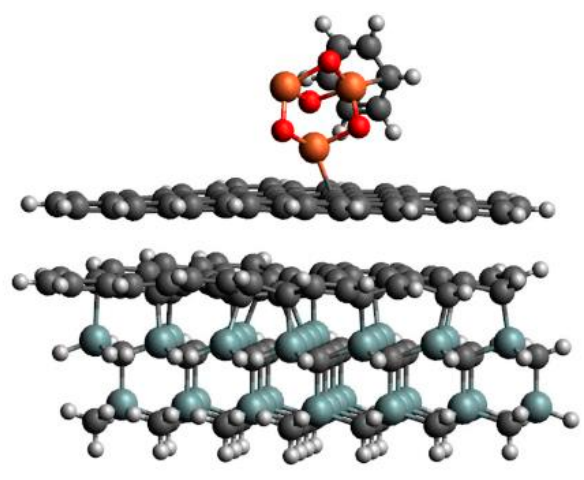

(b)
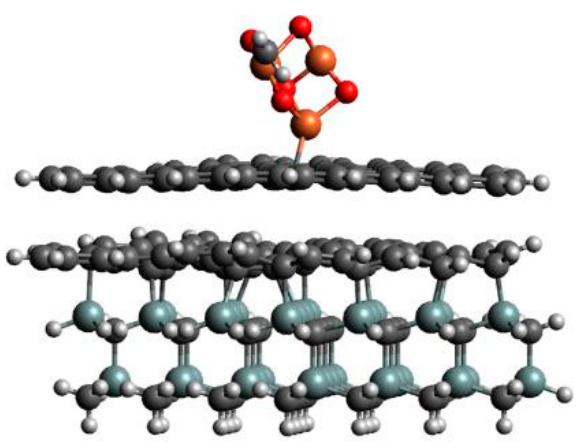

(d)

Figure 4.6: Optimized adsorption configurations of $\mathrm{C}_{6} \mathrm{H}_{6}$ on $\mathrm{PEG}$ (a) and DEG (b), and $\mathrm{CH}_{2} \mathrm{O}$ on PEG (a) and DEG (d) [Paper 2]. 


\subsection{Gas measurements}

To evaluate the performance of the prepared EG-based gas sensors and their applicability in AQM, measurements with several test gases under varying operating conditions, such as sensor temperature and relative humidity of the ambient, have been performed. The sensor's resistance is used as signal and should change when the test gas is introduced. An exemplary response is shown in Figure 4.7, where a $\mathrm{Fe}_{3} \mathrm{O}_{4} \mathrm{NP}$ DEG sensor was exposed to $30 \mathrm{~min}$ pulses of $\mathrm{CH}_{2} \mathrm{O}$ at concentrations from 5 to $0.1 \mathrm{ppm}$.

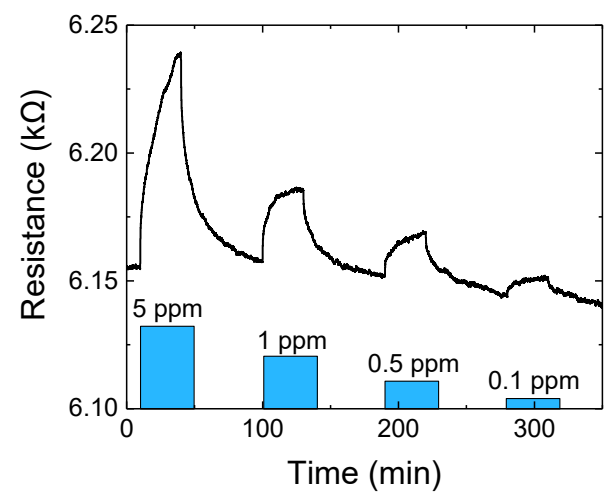

Figure 4.7: Response of $\mathrm{Fe}_{3} \mathrm{O}_{4} \mathrm{NP}$ DEG for $\mathrm{CH}_{2} \mathrm{O}$ exposures at $150{ }^{\circ} \mathrm{C}$ at $0 \% \mathrm{RH}$. Adapted from [Paper 2].

The relative response is then calculated as the relative change in resistance due to the gas exposure in relation to its baseline.

$$
r=\frac{R-R_{0}}{R_{0}} \cdot 100 \%
$$

$R$ is either the saturated resistance signal or the last value of resistance before the gas exposure is switched back to background gas and $R_{0}$ corresponds to the baseline resistance before the gas exposure. In this example, the relative response would be $0.45 \%$ for $1 \mathrm{ppm}$ of formaldehyde. 
If not especially mentioned, all measurements have been performed with a $3 \mathrm{~V}$ measurement voltage over the contacts at $150{ }^{\circ} \mathrm{C}$ in dry air with a gas flow of $100 \mathrm{ml} / \mathrm{min}$.

The only way to get a value for a time constant if the saturated response plateau is not reached is through extrapolation. Here, an exponential fit is applied to the gas response.

$$
y=\mathrm{A}_{1} \mathrm{e}^{-\mathrm{x} / \tau}+\mathrm{y}_{0}
$$

$A_{1}, \tau$ and $y_{0}$ are the fitting parameters, whereof $\tau$ is the time constant defined as when $63 \%$ of the change has happened (also referred to as $\left.\tau_{63}\right)$. In this example, $\tau$ is about $300 \mathrm{~s}$ for 1 ppm exposure.

The signal to noise ratio (SNR) in decibel $(\mathrm{dB})$ is a good value to compare sensor properties and is calculated as

$$
S N R_{d B}=20 \log _{10}\left(\frac{A_{\text {signal }}}{A_{\text {noise }}}\right)
$$

where $\mathrm{A}_{\text {signal }}$ is the maximum absolute response at a given concentration and $\mathrm{A}_{\text {noise }}$ is three times the standard deviation of the baseline noise (also referred to as 30). For the absolute response of $1 \mathrm{ppm}$ shown above $(28 \Omega)$, the standard deviation is $0.32 \Omega$ and the SNR is $29 \mathrm{~dB}$.

\subsubsection{Influence of temperature}

The sensor temperature plays an important role for the sensitivity of gas sensors. To ensure adsorption and reaction of gases at the sensor surface and thus a sensor signal, a specific activation energy has to be overcome [78]. This leads to different relaxation times caused by different rate constants for different gases [79]. As already mentioned, the current sensor setup limits the operating temperature to about $300{ }^{\circ} \mathrm{C}$ and no measurements were performed above $200^{\circ} \mathrm{C}$ as a precaution. To be able to work at higher temperatures, sensors are usually annealed at an even higher temperature, which was not done here. 


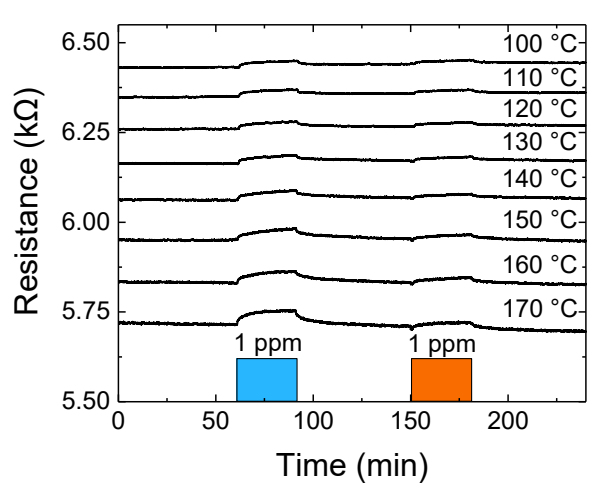

(a)

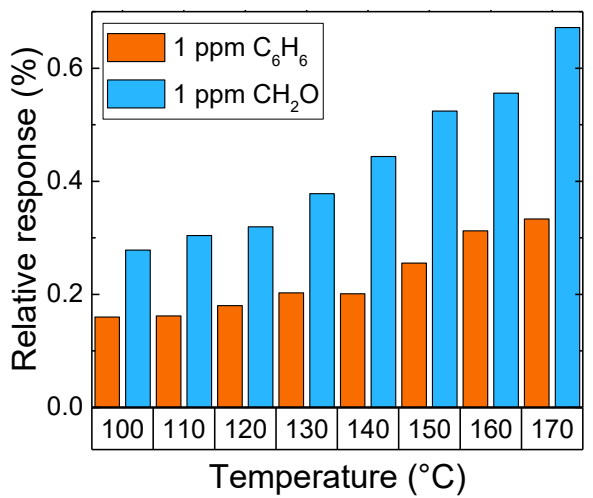

(b)

Figure 4.8: Response of $\mathrm{Fe}_{3} \mathrm{O}_{4}$ NP DEG for $\mathrm{CH}_{2} \mathrm{O}$ and $\mathrm{C}_{6} \mathrm{H}_{6}$ exposures at different temperatures at $0 \% \mathrm{RH}$.

Figure 4.8 shows the response of $\mathrm{Fe}_{3} \mathrm{O}_{4}$ NP DEG towards 1 ppm of $\mathrm{CH}_{2} \mathrm{O}$ (blue) and $\mathrm{C}_{6} \mathrm{H}_{6}$ (red) for $30 \mathrm{~min}$ at temperatures ranging from $100{ }^{\circ} \mathrm{C}$ up to $170{ }^{\circ} \mathrm{C}$ in steps of $10^{\circ} \mathrm{C}$. The measurement clearly shows that the baseline resistance increases with increasing temperature. Moreover, a higher operating temperatures leads to higher responses. The response towards $1 \mathrm{ppm}$ of $\mathrm{CH}_{2} \mathrm{O}$ increases from $0.28 \%$ at $100{ }^{\circ} \mathrm{C}$ to $0.67 \%$ at $170{ }^{\circ} \mathrm{C}$ and from $0.16 \%$ to $0.33 \%$ for $\mathrm{C}_{6} \mathrm{H}_{6}$. Measurements above $150{ }^{\circ} \mathrm{C}$ also exhibit a small drift as the sensors have not been used at those temperatures before. To prevent the formation of a film of water on the sensor surface and achieve a reasonably high response at a fairly stable baseline, all further measurements using $\mathrm{Fe}_{3} \mathrm{O}_{4} \mathrm{NP}$ DEG have been performed with an operating temperature of $150{ }^{\circ} \mathrm{C}$.

A more systematic study of influence of temperature, humidity and UV irradiation influence was performed with the NL DEG samples. The response to 30 min exposure towards 25 and $100 \mathrm{ppm}$ of $\mathrm{NH}_{3}$ was tested at $125,100,75$ and $50{ }^{\circ} \mathrm{C}$ at $50 \% \mathrm{RH}$. In between exposures, the sensor chamber was purged with background gas for $90 \mathrm{~min}$. Figure 4.9 shows the result exemplarily for the $\mathrm{V}_{2} \mathrm{O}_{5}(0.05)$ NL DEG sensor and the responses for all investigated NL samples 
to $25 \mathrm{ppm} \mathrm{NH}_{3}$ are summarized in Table 5. Values marked in bold are the highest observed absolute responses for each sample.

In contrast to the measurement discussed before (Figure 4.8), an increase in temperature means a decrease in response for all samples but $\mathrm{ZrO}_{2}(0.1)$, which has its highest response at $125^{\circ} \mathrm{C}$. $\mathrm{CuO}(0.05)$ exhibits an almost constant response for all temperatures but a lower response at $50{ }^{\circ} \mathrm{C}$. A higher response is, however, not always desired if it comes with slower time constants. This can be clearly seen in Figure 4.9, where only exposures at $125^{\circ} \mathrm{C}$ lead to a steady-state sensor response during the $30 \mathrm{~min}$ gas exposure. $\tau$ is extrapolated for all four operating temperatures and it increases from approximately $150 \mathrm{~s}$ at $125^{\circ} \mathrm{C}$ up to $550 \mathrm{~s}$ at $50{ }^{\circ} \mathrm{C}$. Moreover, at lower temperatures the sensor is not always able to relax back to its baseline after $90 \mathrm{~min}$ at lower temperatures. The response of the $\mathrm{CuO}(0.1)$ sample show that both temperature and gas concentration contribute to the carrier concentration, and thus, the resistance of the sensor. The first exposure at $125^{\circ} \mathrm{C}$ towards $25 \mathrm{ppm}$ of $\mathrm{NH}_{3}$ results in an increase in resistance and a positive response, whereas $100 \mathrm{ppm}$ already leads to a negative response of $-0.6 \%$ (not shown here). The reason for this change in response direction is likely that with increasing gas adsorption enough electrons are donated to the

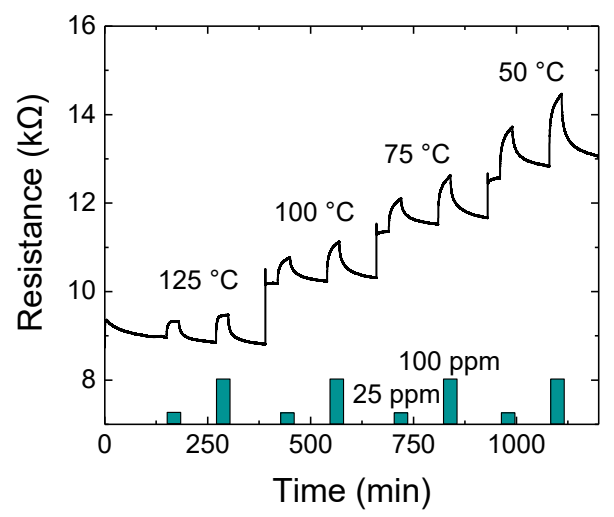

Figure 4.9: Response of $\mathrm{V}_{2} \mathrm{O}_{5}$ (0.05) NL DEG for $\mathrm{NH}_{3}$ exposures at different temperatures at $50 \% \mathrm{RH}$. 
graphene for the Fermi level to move from below the Dirac point (p-type conductivity) to above the Dirac point (n-type conductivity). When changing the temperature to lower degrees, the response is always negative. This would also partly explain why the absolute response increases with lower temperatures as temperature and $\mathrm{NH}_{3}$ concentration work against each other in terms of carrier generation. The other $\mathrm{CuO}$ sample, on the other hand, exhibits a positive response for all temperatures, similar to both $\mathrm{V}_{2} \mathrm{O}_{5}$ sensors. $\mathrm{Fe}_{3} \mathrm{O}_{4}$ and $\mathrm{ZrO}_{2}$ show a negative response for all temperatures.

A compromise between level of response, response shape and relaxation has to be established. As a result of this, all other measurements conducted with NL DEG samples are operated at $75^{\circ} \mathrm{C}$ except for $\mathrm{ZrO}_{2}(0.1)$ at $125^{\circ} \mathrm{C}$.

Table 5: Relative responses of NL DEG sensors towards $25 \mathrm{ppm} \mathrm{NH}_{3}$ at different temperatures at $50 \% \mathrm{RH}$.

\begin{tabular}{l|rrrr} 
& \multicolumn{4}{|c}{ Relative response (\%) } \\
& $125{ }^{\circ} \mathrm{C}$ & $100{ }^{\circ} \mathrm{C}$ & $75{ }^{\circ} \mathrm{C}$ & $50{ }^{\circ} \mathrm{C}$ \\
\hline $\mathrm{CuO}(0.05)$ & 4.6 & 4.6 & $\mathbf{4 . 8}$ & 3.5 \\
$\mathrm{CuO}(0.1)$ & $\mathbf{0 . 9}$ & -0.8 & -2.9 & $\mathbf{- 8 . 3}$ \\
$\mathrm{Fe}_{3} \mathrm{O}_{4}(0.05)$ & -7.6 & -10.8 & -14.1 & $\mathbf{- 1 8 . 9}$ \\
$\mathrm{Fe}_{3} \mathrm{O}_{4}(0.1)$ & -5.9 & -6.5 & -8.1 & $\mathbf{- 1 3 . 5}$ \\
$\mathrm{V}_{2} \mathrm{O}_{5}(0.05)$ & 4.2 & 5.8 & 6.6 & $\mathbf{9 . 2}$ \\
$\mathrm{V}_{2} \mathrm{O}_{5}(0.1)$ & 1.8 & 3.9 & 7.7 & $\mathbf{1 2 . 4}$ \\
$\mathrm{ZrO}_{2}(0.1)$ & $\mathbf{- 2 1 . 2}$ & -14.3 & -8.3 & -8.0
\end{tabular}




\subsubsection{Influence of humidity}

Perhaps even more critical than temperature for the sensor response of some material/gas combinations, is the influence of relative humidity in the ambient. Many metal oxides have been found to exhibit a cross-sensitivity towards $\mathrm{RH}$ and for most materials, a higher level of RH means a lower sensitivity towards other gases, as they must compete with water for available adsorption sites. To explore the optimal sensitivity, most measurements shown are performed in a dry environment. To investigate the effect of $\mathrm{RH}$, measurements with different samples, gases and levels of humidity have been performed.

Figure 4.10 shows the response of $\mathrm{Fe}_{3} \mathrm{O}_{4}$ NP DEG vs 1.6 and $0.8 \mathrm{ppm}$ of $\mathrm{CH}_{2} \mathrm{O}$ and 100 and $200 \mathrm{ppb}$ of $\mathrm{C}_{6} \mathrm{H}_{6}$ for $30 \mathrm{~min}$ at $150{ }^{\circ} \mathrm{C}$ for 50,25 and $0 \% \mathrm{RH}$. No response is observed for any humidity above zero for both gases. This means that the complete sensor system for AQM would need to run in a dry environment. This is a drawback, but technologically possible.

Similar measurements were performed using NL DEG samples at 30 min exposure of $200 \mathrm{ppb} \mathrm{C}_{6} \mathrm{H}_{6}$ and $\mathrm{CH}_{2} \mathrm{O}$ in dry and humid $(50 \% \mathrm{RH})$ conditions using three operating temperatures (150, 100 and $50{ }^{\circ} \mathrm{C}$ ). The measurements performed in dry conditions are discussed in more detail in section 4.2.4. The results of the

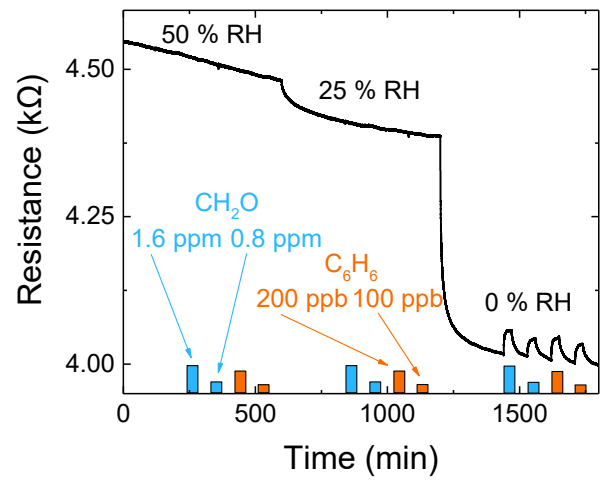

Figure 4.10: Relative response of $\mathrm{Fe}_{3} \mathrm{O}_{4}$ NP DEG for $\mathrm{CH}_{2} \mathrm{O}$ and $\mathrm{C}_{6} \mathrm{H}_{6}$ exposures at $150^{\circ} \mathrm{C}$ at different $\mathrm{RH}$. 


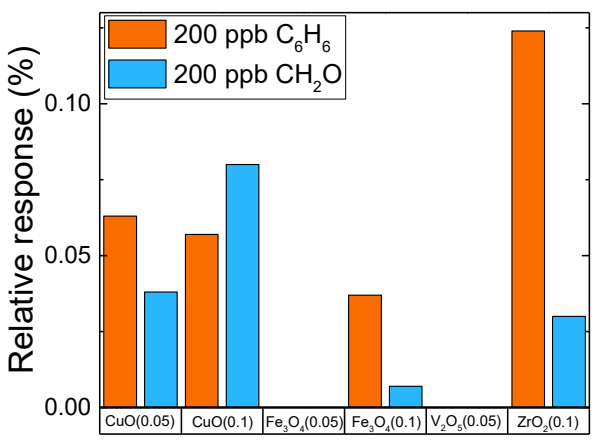

Figure 4.11: Relative responses of NL DEG samples for $\mathrm{C}_{6} \mathrm{H}_{6}$ and $\mathrm{CH}_{2} \mathrm{O}$ exposures at $150{ }^{\circ} \mathrm{C}$ at $50 \% \mathrm{RH}$.

measurements with $50 \% \mathrm{RH}$ at $150{ }^{\circ} \mathrm{C}$ are summarized in Figure 4.11. None of the sensors reacted to the test gases at 100 or $50^{\circ} \mathrm{C}$ and the sensors decorated with $\mathrm{V}_{2} \mathrm{O}_{5}$ did also not react at $150{ }^{\circ} \mathrm{C}$. Similar to what was shown above, $\mathrm{Fe}_{3} \mathrm{O}_{4}(0.05)$ loses its sensitivity towards $\mathrm{C}_{6} \mathrm{H}_{6}$ and $\mathrm{CH}_{2} \mathrm{O}$ under the influence of humidity. $\mathrm{Fe}_{3} \mathrm{O}_{4}(0.1), \mathrm{ZrO}_{2}(0.1)$ and both $\mathrm{CuO}$ DEG sensors show a small response at $150{ }^{\circ} \mathrm{C}$ for both gases. The response is much smaller compared to dry conditions, is not very stable and strongly influenced by drift induced with the introduction of humidity. The highest response towards $\mathrm{C}_{6} \mathrm{H}_{6}$ can be observed for $\mathrm{ZrO}_{2}$ (0.1) with $0.12 \%$. All the NL samples show a lower response for $\mathrm{CH}_{2} \mathrm{O}$ compared to $\mathrm{C}_{6} \mathrm{H}_{6}$, except for $\mathrm{CuO}(0.1)$ which has its highest response towards $\mathrm{CH}_{2} \mathrm{O}$ (0.08\%).

The responses of the different NL DEG samples towards $25 \mathrm{ppm}$ of $\mathrm{NH}_{3}$ for $30 \mathrm{~min}$ at $\mathrm{RH}$ levels of $0,20,40$ and $60 \%$ is shown in Figure 4.12. The operating temperature was kept at $75^{\circ} \mathrm{C}$ for all sensors except $\mathrm{ZrO}_{2}(0.1)$ at $125^{\circ} \mathrm{C}$. All samples exhibit a decrease in sensitivity when changing from a dry environment to a humid one except $\mathrm{V}_{2} \mathrm{O}_{5}$ (0.05), which increases progressively from $8.8 \%$ at $0 \% \mathrm{RH}$ to $13.8 \%$ at $60 \% \mathrm{RH}$. The responses of $\mathrm{Fe}_{3} \mathrm{O}_{4}(0.1)$ and $\mathrm{CuO}(0.05)$ decrease for each humidity step from initially -8.4 and 


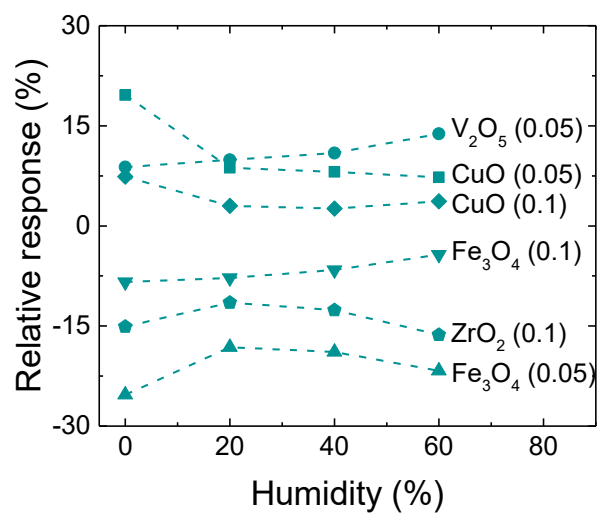

Figure 4.12: Relative responses of $\mathrm{NL} D E G$ samples for $\mathrm{NH}_{3}$ exposures at $75^{\circ} \mathrm{C}$ (except $\mathrm{ZrO}_{2}(0.1)$ at $125^{\circ} \mathrm{C}$ ) at different $\mathrm{RH}$.

$19.6 \%$ in dry conditions down to -4.3 and $7.3 \%$ at $60 \% \mathrm{RH}$, respectively. $\mathrm{Fe}_{3} \mathrm{O}_{4}(0.05)$ and $\mathrm{CuO}(0.1)$, on the other hand, show a drop in resistance for the first humidity level $(20 \% \mathrm{RH})$, then stay almost the same for $40 \% \mathrm{RH}$ and increase for $60 \% \mathrm{RH}$. It is interesting that an increase in humidity increases the response again for some samples, even exceeding the response at zero humidity $\left(\mathrm{ZrO}_{2}(0.1)\right)$. This increase could be due to the reaction with $\mathrm{OH}$ groups or of products of reactions from $\mathrm{OH}$ groups and $\mathrm{NH}_{3}$ instead. This phenomenon was shown to occur for metal oxide gas sensors when operating them at relatively low temperatures in a humid environment [80], [81].

\subsubsection{Influence of UV irradiation}

Figure 4.13 shows the response of a $\mathrm{TiO}_{2} \mathrm{NP}$ DEG sensor towards varying oxygen percentages without (black) and with UV irradiation (purple). The UV LED has a wavelength of $265 \mathrm{~nm}$ and an optical output power of $0.8 \mathrm{~mW}$. The operating temperature was $100{ }^{\circ} \mathrm{C}$ and oxygen was varied from a baseline of $20 \%$ to values between 16 and $1 \%$. It can be clearly seen that the measurement without UV irradiation shows changes in resistance when varying the oxygen concentration, but they are not distinct and cannot be 


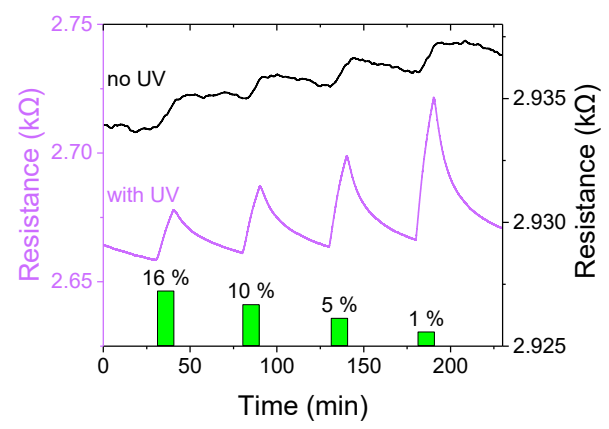

Figure 4.13: Relative response of $\mathrm{TiO}_{2} \mathrm{NP}$ DEG towards a change of oxygen from a background of $20 \%$ to between 16 and $1 \%$ without (black) and with UV irradiation (purple, $265 \mathrm{~nm}$ ) at $100{ }^{\circ} \mathrm{C}$ at $0 \% \mathrm{RH}$. Adapted from [Paper 1].

related to the specific concentrations. Introducing the UV irradiation, the baseline resistance drops by about $270 \Omega$. Moreover, the changes in oxygen concentration can now be distinctively observed as the resistance shows the typical shape of a gas sensor response. Unfortunately, the exposure time is with $10 \mathrm{~min}$ not enough to arrive at a saturated response level. The desorption process is enhanced under the irradiation as well, decreasing the time needed for the sensor to get back to its baseline after the gas exposure, making it faster and more effective. The low response without UV is likely due to an oxygen saturated surface in the background of $20 \%$ $\mathrm{O}_{2}$. UV irradiation promotes oxygen desorption, leading to an increased dynamic range for oxygen detection.

The influence of different UV wavelengths on the sensor response towards an exposure of $25 \mathrm{ppm} \mathrm{NH}_{3}$ for $30 \mathrm{~min}$ is summarized for the NL DEG samples in Table 6. Values marked in bold are the highest observed absolute responses for each sample. The relative humidity was kept at $50 \%$ and all samples were operated at $75^{\circ} \mathrm{C}$ except $\mathrm{ZrO}_{2}(0.1)$ at $125{ }^{\circ} \mathrm{C}$. A clear trend for $\mathrm{V}_{2} \mathrm{O}_{5}$ can be observed as the relative sensor response is highest (14.3 and $13.3 \%$ ) at $355 \mathrm{~nm}$ UV irradiation and decreases over $265 \mathrm{~nm}$ down to no irradiation for both samples. For $\mathrm{ZrO}_{2}$, on the other hand, only a 
small decrease is observed for UV irradiation (both wavelengths) compared to $-21.3 \%$ with no irradiation. $\mathrm{Fe}_{3} \mathrm{O}_{4}$ also exhibits a negative response and without UV irradiation, the response is lowest for both samples. $\mathrm{Fe}_{3} \mathrm{O}_{4}(0.05)$ shows a higher response for all three conditions compared to $\mathrm{Fe}_{3} \mathrm{O}_{4}(0.1)$, but has its highest absolute response with $-19.4 \%$ at $265 \mathrm{~nm}$ UV irradiation, while $\mathrm{Fe}_{3} \mathrm{O}_{4}(0.1)$ has its highest response (-15.2\%) at $355 \mathrm{~nm}$ UV irradiation. $\mathrm{CuO}(0.05)$ exhibits a small but positive response (1.9\%) at $355 \mathrm{~nm}$ UV irradiation but changes its direction of response at $265 \mathrm{~nm}$ UV irradiation, while giving the highest response of $-4.8 \%$ without irradiation. This indicates that the UV irradiation pushes the Fermi level through the Dirac point, hence switching the conduction behavior. $\mathrm{CuO}(0.1)$ reacts similar to $\mathrm{V}_{2} \mathrm{O}_{5}$ with the highest response $(-14.3 \%)$ at $355 \mathrm{~nm}$ UV irradiation and a decrease without irradiation.

Moreover, UV irradiation has also an effect on the time constant for some samples. For example, $\tau$ decreases for $\mathrm{V}_{2} \mathrm{O}_{5}$ from approximately $550 \mathrm{~s}$ without irradiation down to $400 \mathrm{~s}$ at $265 \mathrm{~nm}$ UV irradiation at $75^{\circ} \mathrm{C}$ operating temperature. $\mathrm{CuO}$ behaves similarly with a drop about $200 \mathrm{~s}$ from 600 down to $400 \mathrm{~s}$ with $265 \mathrm{~nm}$ UV irradiation. An irradiation with $355 \mathrm{~nm}$ does decrease $\tau$ as well, but not as much as $265 \mathrm{~nm}$ UV irradiation. This could be due to irradiation with a shorter wavelength has a higher energy. For $\mathrm{Fe}_{3} \mathrm{O}_{4}$, on the other hand, $\tau$ stays approximately constant at $350 \mathrm{~s}$ with and without UV irradiation.

The whole sensing mechanism for DEG is not fully understood and introducing one more variable like UV irradiation introduces additional complexity. It is known that if the band gap is below the wavelength energy (4.48 eV for $265 \mathrm{~nm}$ and $3.49 \mathrm{eV}$ for $355 \mathrm{~nm}$ ), there will be charge excitation changing the charge density also in the graphene. This could increase or counteract the effect of the gas response depending on the material/gas combination and should be more pronounced for the thicker layers, where the net charge excitation is higher. This also explains why $\mathrm{ZrO}_{2}$, with a band gap $>5 \mathrm{eV}$, shows no significant difference under UV irradiation. 
Table 6: Relative responses of NL DEG sensors towards $25 \mathrm{ppm} \mathrm{NH}_{3}$ at $50 \% \mathrm{RH}$ with different $\mathrm{UV}$ wavelengths at $75^{\circ} \mathrm{C}$ except $\mathrm{ZrO}_{2}(0.1)$ at $125^{\circ} \mathrm{C}$.

\begin{tabular}{l|rrr} 
& \multicolumn{4}{|c}{ Relative response (\%) } \\
& $\mathrm{No} \mathrm{UV}$ & $265 \mathrm{~nm}$ & $355 \mathrm{~nm}$ \\
\hline $\mathrm{CuO}(0.05)$ & $\mathbf{- 4 . 8}$ & -0.002 & $\mathbf{1 . 9}$ \\
$\mathrm{CuO}(0.1)$ & -2.9 & -12.2 & $\mathbf{- 1 4 . 3}$ \\
$\mathrm{Fe}_{3} \mathrm{O}_{4}(0.05)$ & -14.1 & $\mathbf{- 1 9 . 4}$ & -18.7 \\
$\mathrm{Fe}_{3} \mathrm{O}_{4}(0.1)$ & -8.1 & -11.8 & $\mathbf{- 1 5 . 2}$ \\
$\mathrm{V}_{2} \mathrm{O}_{5}(0.05)$ & 7.7 & $/ 6$ & $\mathbf{1 4 . 3}$ \\
$\mathrm{V}_{2} \mathrm{O}_{5}(0.1)$ & 6.6 & 11.2 & $\mathbf{1 3 . 3}$ \\
$\mathrm{ZrO}_{2}(0.1)$ & $\mathbf{- 2 1 . 3}$ & -19.4 & -19.3
\end{tabular}

\subsubsection{Ammonia}

The two best performing NL DEG sensors from measurements described above were used to test their capabilities of detecting ppb concentrations of $\mathrm{NH}_{3}$ in a humid environment (see Figure 4.14). This is done to evaluate their capabilities for the application in breath analysis towards $\mathrm{NH}_{3}$ as target gas. Hibbard and Killard state that there is a need of simple, non-invasive detection methods that can detect ammonia with a limit of detection of at least $50 \mathrm{ppb}$ [82].

Similar to what was observed above, $\mathrm{Fe}_{3} \mathrm{O}_{4}(0.05)$ shows the highest response towards $\mathrm{NH}_{3}$ and exhibits with $-4.8 \%$ towards $100 \mathrm{ppb}$ more than twice the response of $\mathrm{V}_{2} \mathrm{O}_{5}$ (0.05). Moreover, the SNR for $\mathrm{Fe}_{3} \mathrm{O}_{4}(0.05)$ is with $47 \mathrm{~dB}$ better than the one for $\mathrm{V}_{2} \mathrm{O}_{5}$ (0.05) with $30 \mathrm{~dB}$ at $100 \mathrm{ppb}$. Although the response is not perfectly distinct for all tested concentrations, the lower detection limit should be much

${ }^{6} \mathrm{~V}_{2} \mathrm{O}_{5}(0.05)$ broke down and could not be used for further measurements. 


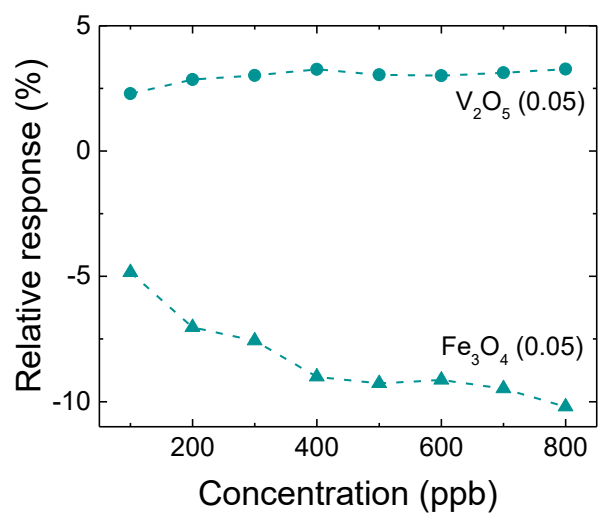

Figure 4.14: Relative response of $\mathrm{V}_{2} \mathrm{O}_{5}(0.05)$ and $\mathrm{Fe}_{3} \mathrm{O}_{4}(0.05)$ NL DEG samples for $\mathrm{NH}_{3}$ exposures at $75{ }^{\circ} \mathrm{C}$ at $40 \% \mathrm{RH}$.

less than the tested $100 \mathrm{ppb}$ considering the high SNR value. Assuming the worst case scenario of a linear relation between response in $\Omega$ and concentration in ppb, the lower detection limit can be extrapolated as $0.5 \mathrm{ppb}$ assuming that the response has to be larger than $3 \sigma$. This, and the fact that it operates well under humid conditions at a relatively low temperature, would make this NL DEG a promising platform for breath analysis. Note that the human breath usually has a relative humidity of 91-96\% [82], but measurements could only be performed up to $60 \% \mathrm{RH}$. Moreover, the dynamic range of response towards $\mathrm{NH}_{3}$ is with at least three orders of magnitude quite broad. One of the main drawbacks though are still the slow ad- and desorption times. This issue is addressed in section 4.3.

\subsubsection{Nitrogen dioxide}

$\mathrm{Fe}_{3} \mathrm{O}_{4}$ NP DEG samples were also tested at low concentrations of $\mathrm{NO}_{2}$ at $150{ }^{\circ} \mathrm{C}$ in a dry environment. The gas was applied for $15 \mathrm{~min}$ followed by a background exposure of $60 \mathrm{~min}$. More measurements using $\mathrm{NO}_{2}$ are discussed in section 4.3, where the response towards $\mathrm{NO}_{2}$ is exemplarily used to test the introduction of the first-order time-derivative signal. Here, the sensor was only tested for 100 , 


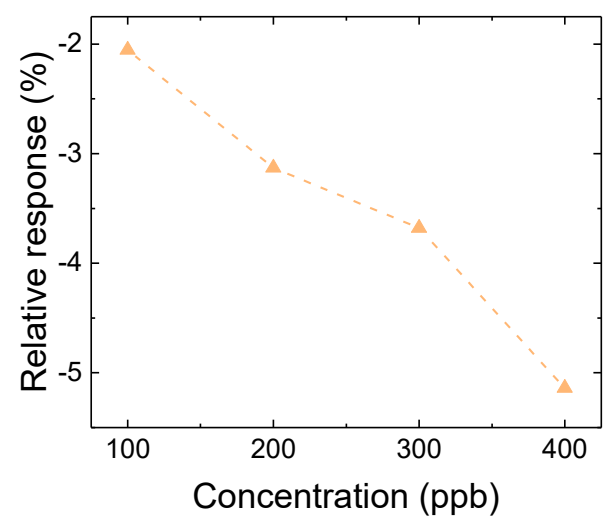

Figure 4.15: Relative response of $\mathrm{Fe}_{3} \mathrm{O}_{4}$ NP DEG for $\mathrm{NO}_{2}$ exposures at $150{ }^{\circ} \mathrm{C}$ at $0 \% \mathrm{RH}$.

200, 300 and $400 \mathrm{ppb}$ and the response over concentration is fairly linear in that region (see Figure 4.15). The response towards $\mathrm{NO}_{2}$ is negative - for example $-2 \%$ at $100 \mathrm{ppb}$ - which makes it clearly distinguishable from all the positive responses observed so far for the NP DEG samples for exposures of $\mathrm{NH}_{3}, \mathrm{C}_{6} \mathrm{H}_{6}$ and $\mathrm{CH}_{2} \mathrm{O}$. The time constant $\tau$ is approximately $500 \mathrm{~s}$ for $100 \mathrm{ppb}$ exposure. The SNR $(87 \mathrm{~dB})$ at $100 \mathrm{ppb}$ hints to a much lower detection limit than the tested concentrations. Assuming again a linear correlation and a detectable response larger than $3 \sigma$, the lower detection limit can be extrapolated to be approximately $1.5 \mathrm{ppb}$. This value demonstrates that the hourly average of $20 \mathrm{ppb} \mathrm{NO}_{2}$ exposure for AQM could easily be detected and could even outperform state of the art commercial sensors, such as NO2-A1 from Alphasense (Essex, United Kingdom) with a resolution of $20 \mathrm{ppb}$.

\subsubsection{Benzene and Formaldehyde}

One of the main findings of this work is the ability to detect the hazardous VOC, $\mathrm{C}_{6} \mathrm{H}_{6}$ and $\mathrm{CH}_{2} \mathrm{O}$ quantitatively down to a single ppb and also over a large dynamic range of three orders of magnitude up to at least 5 ppm using $\mathrm{Fe}_{3} \mathrm{O}_{4}$ NP DEG sensors. The measurement shown in Figure 4.16 was performed at $150{ }^{\circ} \mathrm{C}$ at $0 \% \mathrm{RH}$. 
The relative response is with $0.02 \%$ and $0.04 \%$ for 1 ppb of $\mathrm{C}_{6} \mathrm{H}_{6}$ and $\mathrm{CH}_{2} \mathrm{O}$ not very large, but with a SNR of $1.6 \mathrm{~dB}$ for 5 ppb of $\mathrm{C}_{6} \mathrm{H}_{6}$ still easily detectable. The discussed measurement was performed at Saarland University, but using the same sensor at Linköping University can even improve the SNR to $35 \mathrm{~dB}$ for 5 ppb $\mathrm{C}_{6} \mathrm{H}_{6} .{ }^{7}$ The WHO recommended safety limit for $\mathrm{CH}_{2} \mathrm{O}$ (81 ppb over 30 min of exposure) is easily reached with a relative response above $0.1 \%$. The time constant $\tau$ lies around $300 \mathrm{~s}$ for both gases. The shown measurement was repeated twice in the same environment and once more approximately one year later with the same sensor. The measured responses show some small deviations between the measurements but without a clear trend of decreasing response over time. This is good as it shows the long-term stability of the sensor. What decreases though is the SNR. More noise can be seen for a sensor if operated over a longer time compared to a 'fresh' sample.

As already mentioned in section 4.2.2, NL DEG samples were tested towards $200 \mathrm{ppb}$ of $\mathrm{C}_{6} \mathrm{H}_{6}$ and $\mathrm{CH}_{2} \mathrm{O}$ as well. The operating temperature was set to 150,100 and $50{ }^{\circ} \mathrm{C}$ with $30 \mathrm{~min}$ of gas

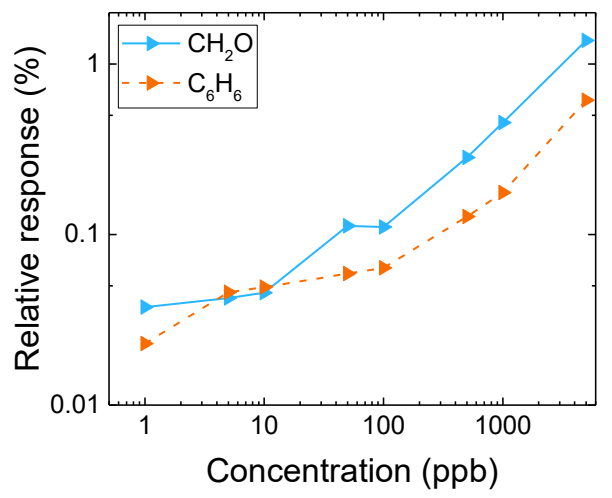

Figure 4.16: Relative response of $\mathrm{Fe}_{3} \mathrm{O}_{4}$ NP DEG for $\mathrm{CH}_{2} \mathrm{O}$ and $\mathrm{C}_{6} \mathrm{H}_{6}$ exposures at $150{ }^{\circ} \mathrm{C}$ at $0 \% \mathrm{RH}$. Adapted from [Paper 2].

\footnotetext{
${ }^{7}$ Measurements performed at Saarland University exhibit a much higher background noise compared to measurements performed at Linköping University.
} 
exposure and $60 \mathrm{~min}$ of relaxation phase in between exposures. The responses for $150{ }^{\circ} \mathrm{C}$ are summarized in Figure 4.17 . At $150{ }^{\circ} \mathrm{C}$, the response towards $\mathrm{C}_{6} \mathrm{H}_{6}$ was higher compared to $\mathrm{CH}_{2} \mathrm{O}$ for all samples. $\mathrm{CuO}(0.1)$ exhibited with $1.9 \%$ and $1.8 \%$ for $\mathrm{C}_{6} \mathrm{H}_{6}$ and $\mathrm{CH}_{2} \mathrm{O}$, respectively, the absolute highest response for all samples. Table 7 summarizes the responses for 50 and $100{ }^{\circ} \mathrm{C}$. Values marked in bold are the highest observed absolute responses for each sample. It can be seen that at lower temperatures the response towards $\mathrm{CH}_{2} \mathrm{O}$ is slightly higher compared to $\mathrm{C}_{6} \mathrm{H}_{6}$ for $\mathrm{Fe}_{3} \mathrm{O}_{4}$ and $\mathrm{V}_{2} \mathrm{O}_{5}$. $\mathrm{ZrO}_{2}$ was only able to detect the gases at $150{ }^{\circ} \mathrm{C}$ and also $\mathrm{Fe}_{3} \mathrm{O}_{4}(0.05)$ and $\mathrm{V}_{2} \mathrm{O}_{5}(0.05)$ showed no response at $50{ }^{\circ} \mathrm{C}$. The highest response in total was observed from $\mathrm{CuO}(0.1)$ at $50{ }^{\circ} \mathrm{C}$ with $3 \%$ and $2.25 \%$ for $\mathrm{C}_{6} \mathrm{H}_{6}$ and $\mathrm{CH}_{2} \mathrm{O}$, respectively. Time constants vary for the different materials and are between 100-200 s and 100-400 s for $\mathrm{C}_{6} \mathrm{H}_{6}$ and $\mathrm{CH}_{2} \mathrm{O}$, respectively. The fastest response for both gases was achieved with $\mathrm{CuO}$ and $\mathrm{V}_{2} \mathrm{O}_{5}\left(\sim 100\right.$ s) and the slowest with $\mathrm{ZrO}_{2}$ (200 and $400 \mathrm{~s}$ ).

Comparing these results under dry conditions with the ones of NP DEG, it seems that the NL samples show a higher response towards $\mathrm{C}_{6} \mathrm{H}_{6}$ and $\mathrm{CH}_{2} \mathrm{O}$. Even more promising though is the response of $\mathrm{CuO}$ NL DEG under humid conditions, where still a response, even if rather small, can be observed. This is promising in

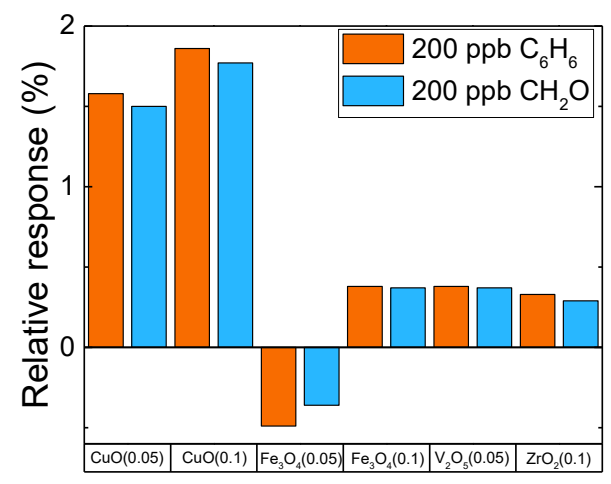

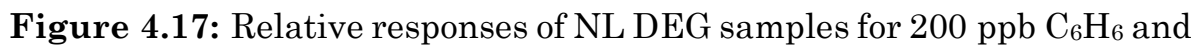
$\mathrm{CH}_{2} \mathrm{O}$ exposures at $150{ }^{\circ} \mathrm{C}$ at $0 \% \mathrm{RH}$. 
Table 7: Relative responses of NL DEG samples for 200 ppb $\mathrm{C}_{6} \mathrm{H}_{6}$ and $\mathrm{CH}_{2} \mathrm{O}$ exposures at 50 and $100{ }^{\circ} \mathrm{C}$ at $0 \% \mathrm{RH}$.

\begin{tabular}{l|lc|cc} 
& \multicolumn{4}{|c|}{ Relative response (\%) } \\
& \multicolumn{2}{|c|}{$\mathrm{C}_{6} \mathrm{H}_{6}$} & \multicolumn{2}{c}{$\mathrm{CH}_{2} \mathrm{O}$} \\
& $50{ }^{\circ} \mathrm{C}$ & $100{ }^{\circ} \mathrm{C}$ & $50{ }^{\circ} \mathrm{C}$ & $100{ }^{\circ} \mathrm{C}$ \\
\hline $\mathrm{CuO}(0.05)$ & 1.7 & 1.3 & 1.5 & 1.1 \\
$\mathrm{CuO}(0.1)$ & 3.0 & 1.9 & 2.3 & 1.6 \\
$\mathrm{Fe}_{3} \mathrm{O}_{4}(0.05)$ & 0 & 0.07 & 0 & 0.08 \\
$\mathrm{Fe}_{3} \mathrm{O}_{4}(0.1)$ & 0.8 & 0.4 & 0.8 & 0.5 \\
$\mathrm{~V}_{2} \mathrm{O}_{5}(0.05)$ & 0 & 0.1 & 0 & 0.13 \\
$\mathrm{ZrO}_{2}(0.1)$ & 0 & 0 & 0 & 0
\end{tabular}

so far as it would work for AQM without the problem of interfering humidity. More investigations with lower concentrations are needed to verify the applicability for AQM.

\subsection{First-order time-derivate signal}

As already mentioned before, a sensor with good sensitivity is not sufficient and properties like stability, selectivity and speed of response need to be addressed as well. One method to achieve faster time constants is the use of the sensor signal's first-order time-derivative [12]. In this section, the sensor response is evaluated based on the first-order time-derivative to introduce an alternative sensor signal. The response is calculated as

$$
r_{d t}=R_{d t}-R_{0, d t}
$$

$R_{\mathrm{dt}}$ is the highest absolute derivative signal during a gas pulse and $R_{0, d t}$ is the baseline value before gas exposure. For most sensors, 
further smoothening is necessary to eliminate the rapid fluctuations in the resistance value due to background noise. In this work, an adjacent average filter with 10 points smoothening was used if not specified otherwise.

Figure 4.18 shows the resistance over time of $\mathrm{Fe}_{3} \mathrm{O}_{4}$ NP DEG (upper black line) when exposed to different $\mathrm{NO}_{2}$ concentrations for $15 \mathrm{~min}$. This is the same raw data used to calculate the response in Figure 4.15. It can be clearly seen that $15 \mathrm{~min}$ of exposure is not enough for the sensor to reach a saturated response. During the recovery time of $60 \mathrm{~min}$, it was also not possible for the sensor to fully relax to its initial baseline. This is a common problem for rather slow reacting sensors. If the signal does not reach a saturated response level during the exposure, it is not straightforward to calculate the real maximum response and, moreover, also the common time constants like $\tau_{90}$ cannot be calculated easily but need to be extrapolated. Therefore, a direct comparison with sensor performances reported in literature and product specification sheets is not possible. To overcome these issues without adding more exposure or relaxation time, the first-order time-derivative of the sensor resistance is introduced as an alternative sensor signal (see lower red line in Figure 4.18). Note that here the smoothening was performed with a 100 point window as the baseline signal was very

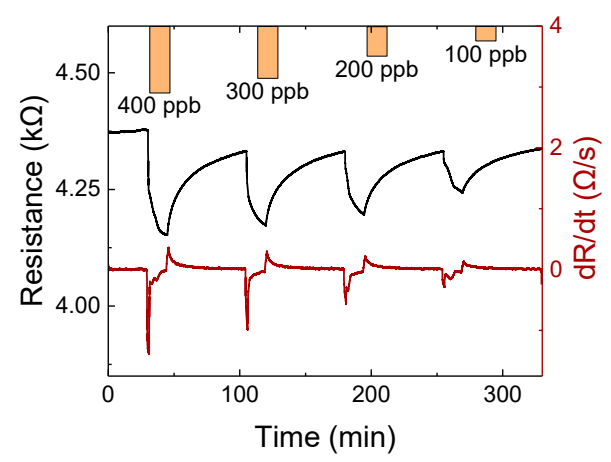

Figure 4.18: Resistance over time of $\mathrm{Fe}_{3} \mathrm{O}_{4}$ NP DEG (black, upper) with its corresponding time-derivative (red, lower) for $\mathrm{NO}_{2}$ exposures at $150{ }^{\circ} \mathrm{C}$ at $0 \% \mathrm{RH}$. 
noisy. This will be discussed in more detail in section 4.3.3. The peaks of the first-order time-derivative signal arise much faster and are also concentration-dependent, which is in good agreement with Wu et al., stating that $r_{d t}$ is directly proportional to the applied gas concentration [12]. Moreover, the desorption peak is concentrationdependent as well. The desorption response is normally not utilized as a standard indicator as it occurs after the adsorption, but it might be useful as a feature in multivariate statistics for selectivity enhancement [83]. Because the peak is reached much faster, it is also more robust against not sufficiently long exposure or relaxation times.

In the following sections, the influence of exposure and relaxations times, as well as of environmental factors such as temperature, humidity and UV irradiation are discussed. At the end, the time constants for all the investigated samples are compared to their corresponding alternative first-order time-derivative time constants.

\subsubsection{Influence of exposure and relaxation time}

If the exposure time is not long enough for the sensor to reach a saturated response, the maximum response increases with increasing exposure time, potentially leading to a misquantification. As the first-order time-derivative of the resistance signal is the slope of the change, it should be independent of the exposure time (if the exposure time is long enough for $r_{d t}$ to reach its peak). Exactly this phenomenon can be seen in Figure 4.19 (a). The sensor response towards 50 ppb $\mathrm{NO}_{2}$ increases from $-0.2 \%$ after 5 min to $-0.9 \%$ after $20 \mathrm{~min}$. On the other hand, $r_{d t}$ is reached must faster and remains at approximately $-0.1 \Omega / \mathrm{s}$, regardless of the exposure time. Note that a slight increase can be observed after the third (15 min) exposure time. The constant time-derivative response could be due to $r_{d t}$ being determined by the initial adsorption/desorption phase during which the change in resistance is the highest. After this, 


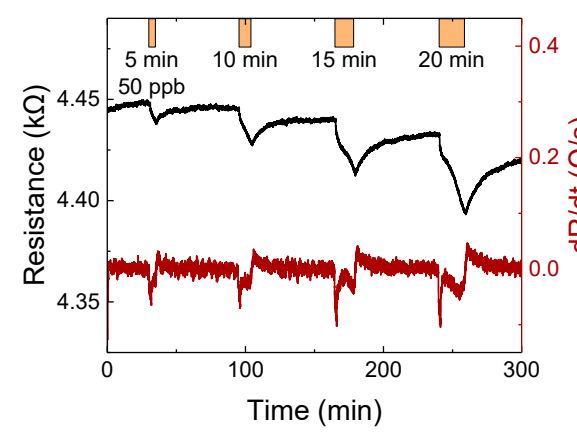

(a)

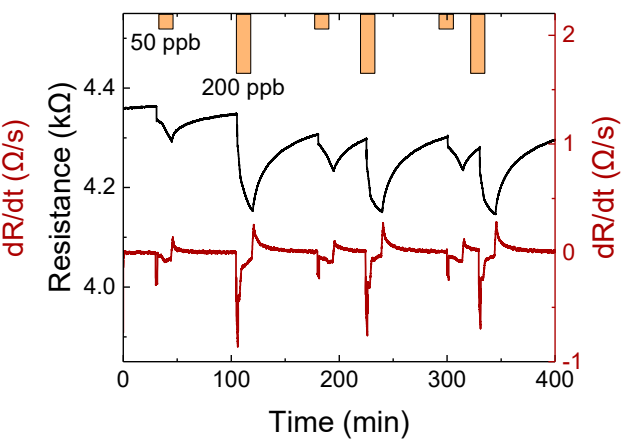

(b)

Figure 4.19: Resistance over time of $\mathrm{Fe}_{3} \mathrm{O}_{4}$ NP DEG (black, upper) with its corresponding time-derivative (red, lower) for $\mathrm{NO}_{2}$ exposures at $150{ }^{\circ} \mathrm{C}$ at $0 \% \mathrm{RH}$ with different (a) exposure and (b) relaxation times.

further adsorption/desorption proceeds at a slower speed.

Figure 4.19 (b) shows the sensor behavior with decreasing relaxation times. Here, the sensor was repeatedly exposed to 50 and $200 \mathrm{ppb} \mathrm{NO}_{2}$ for $15 \mathrm{~min}$, but altering the relaxation time from initially 60 down to $15 \mathrm{~min}$. If the sensor is not able to fully relax to its initial baseline between gas exposures, a drift is induced which could lead to a possible misquantification of the measured gas concentration. Not only does the response magnitude decrease with decreasing relaxation time, also the ratio of response for $200 \mathrm{ppb}$ over $50 \mathrm{ppb}$ gradually decreases from 2.8 to 2.0 for relaxation times of 60 and 15 minutes, respectively. This is a clear indication of $\mathrm{NO}_{2}$ molecules still occupying possible adsorption sites on the sensor surface.

The baseline of the first-order time-derivative signal relaxes much faster, thus exhibiting a constant ratio of responses at $200 \mathrm{ppb}$ over $50 \mathrm{ppb}(3.0 \pm 0.1)$. This results in a problem-free quantification of both concentration at all tested relaxation times. 


\subsubsection{Environmental influences}

It is known that not only the sensor response but also the speed of response heavily depends on the sensor temperature [79]. Considering this, also the first-order time-derivative signal should change with a change in temperature. Figure 4.20 shows the derivative response of Figure 4.9. The response of $\mathrm{V}_{2} \mathrm{O}_{5}$ (0.05) NL DEG is plotted over sensor temperature towards exposures of $25 \mathrm{ppm} \mathrm{NH}_{3}$ exposures. As expected, the time-derivative response exhibits the same trend towards increasing temperature as what was observed for the standard response. The time needed for the derivative signal to reach its maximum although is not significantly dependent on the temperature and stays at around $15 \mathrm{~s}$. This is unexpected, but could be due the relatively small tested temperature range, thus only small changes might occur. This was also evaluated for measurements of $\mathrm{Fe}_{3} \mathrm{O}_{4}$ NP DEG and all NL DEG samples for $\mathrm{C}_{6} \mathrm{H}_{6}$ and $\mathrm{CH}_{2} \mathrm{O}$ exposures (compare section 4.2.6). The time-derivative response for different temperatures follows the standard response. $\tau d t$ is not increasing with decreasing temperature, but stays approximately constant at $15 \mathrm{~s}$.

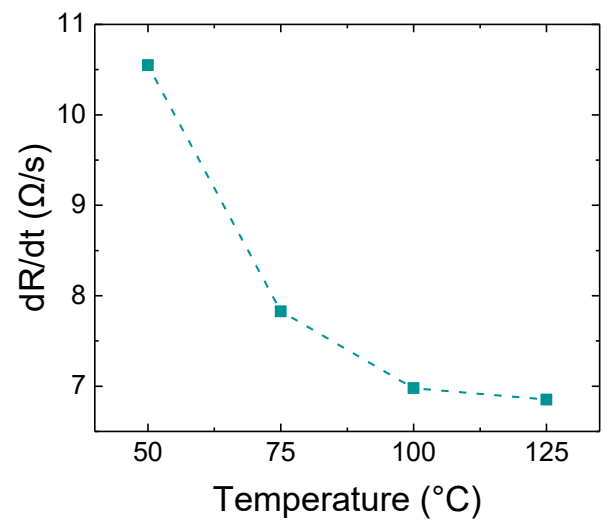

Figure 4.20: Derivative response of $\mathrm{V}_{2} \mathrm{O}_{5}(0.05) \mathrm{NL}$ DEG for 25 ppm $\mathrm{NH}_{3}$ exposures at different temperatures at $50 \% \mathrm{RH}$ (see Figure 4.9). 
The responses towards exposures of $25 \mathrm{ppm} \mathrm{NH}_{3}$ with varying $\mathrm{RH}$ investigated in section 4.2.2 (compare Figure 4.12) were analyzed towards changes in the first-order time-derivative response. For simplicity, only one sensor for each decoration material is shown. The changes in response for different $\mathrm{RH}$ levels is similar to what was observed before for the standard response. More interesting is the time needed to reach $r_{d t}$. As shown in Figure 4.21, the time to peak increases if humidity is introduced. The strongest influence could be observed for $\mathrm{CuO}(0.1)$, where $\tau_{\mathrm{dt}}$ increased from $12 \mathrm{~s}$ at $0 \% \mathrm{RH}$ up to at $32 \mathrm{~s}$ at $60 \% \mathrm{RH}$. This could be due to water molecules occupying possible reaction sites, or a competition between $\mathrm{H}_{2} \mathrm{O}$ and $\mathrm{NH}_{3}$ over available sites, and/ or reactions between the two molecules to form ammonium and hydroxyl groups on the sensor surface, thus limiting the reaction time.

Also the UV measurements from section 4.2.3 (compare Table 6) were analyzed towards changes in the first-order time-derivative response. It was found that the time-derivative response follows the same pattern as the standard response discussed before. However, the time to peak ( $\tau_{\mathrm{dt}}$ ) does not change distinctively with or without UV irradiation and stays at approximately $15 \pm 5 \mathrm{~s}$ for an exposure towards $25 \mathrm{ppm} \mathrm{NH}_{3}$. This is unexpected, as with a higher surface energy through the UV irradiation, also the surface reactions with the gas molecules should be increased, resulting in shorter time to peak in the time-derivative signal. The time constants are already very short and therefore, an additional small decrease is simply not observed. 


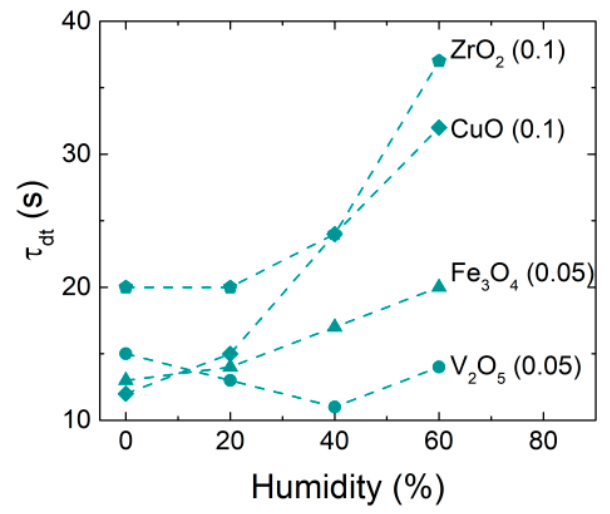

Figure 4.21: $\tau_{\mathrm{dt}}$ of first-order time-derivative response of NL DEG samples for $25 \mathrm{ppm} \mathrm{NH}_{3}$ exposures at $75^{\circ} \mathrm{C}$ (except $\mathrm{ZrO}_{2}(0.1)$ at $125^{\circ} \mathrm{C}$ ) at different $\mathrm{RH}$.

\subsubsection{Time constants}

Especially for indoor air quality monitoring, the sampling rate should be as fast as possible and within a range of a few minutes to allow real-time monitoring [9]. As already mentioned above, the peaks of the derivative signal reach their highest points already after a short period of time. A comparison between the standard response times and their corresponding first-order time-derivative response times for the different material/gas combinations tested is presented in Table 8. For better comparability, all time-derivative calculations were evaluated with a 10 point smoothening. $\tau$ is shown as a range for all NL samples and $\tau_{d t}$ is shown as the average of all NL samples. The time needed to reach $r_{d t}$ depends on the combination of sensor material and test gas, but should be applicable to all resistive type gas sensors. $\tau_{d t}$ of the example figure for $\mathrm{Fe}_{3} \mathrm{O}_{4} \mathrm{NP}$ DEG towards $\mathrm{NO}_{2}$ exposure lies around $10 \mathrm{~s}$ (Figure 4.18) which is 25 times faster compared to the extrapolated time constant of the standard response. Other measurements suggest a decrease of time constants from approximately $300 \mathrm{~s}$ down to $50 \mathrm{~s}$ for measurements 
with the same sensor towards $\mathrm{C}_{6} \mathrm{H}_{6}$ and $\mathrm{CH}_{2} \mathrm{O}$ [Paper 2] $]^{8}$. For a $\mathrm{TiO}_{2}$ NP DEG sample, the time constants with oxygen measurements could be decreased from $1500 \mathrm{~s}$ down to $25 \mathrm{~s}$ [Paper 1] $]^{9}$. This is an improvement with a factor of 60 times faster response compared to the standard resistance signal. For the NL samples an average $\tau_{\mathrm{dt}}$ of $10 \mathrm{~s}$ was found for exposures towards $200 \mathrm{ppb} \mathrm{C}_{6} \mathrm{H}_{6}$ and $\mathrm{CH}_{2} \mathrm{O}$. $\tau_{\mathrm{dt}}$ for $25 \mathrm{ppm} \mathrm{NH}_{3}$, however, lies around $15 \pm 5 \mathrm{~s}$. For most samples, the time-derivative response for $100 \mathrm{ppm}$ exposures was about 5 seconds faster compared to $25 \mathrm{ppm}$. This could be because more gas molecules are available directly from the start of the gas exposure, thus more active surface sites can react at the same time. Moreover, the UV irradiation did not seem to have an effect on $\tau_{\mathrm{d} t}$ for any of the studied material combinations or gases.

The first-order time-derivative signal can get very noisy if the resistance signal does not exhibit a very smooth baseline. Therefore, an adjacent average smoothening filter was used. However, $\tau_{d t}$ highly depends on the applied smoothening filter. Figure 4.22 shows a zoomed in version of the third peak (exposure towards

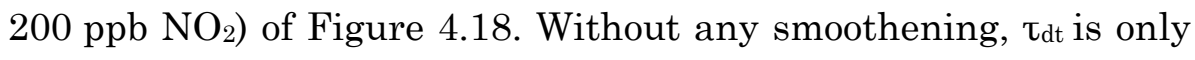
$5 \mathrm{~s}$, whereas it increases to $10 \mathrm{~s}$ for 10 point smoothening and $100 \mathrm{~s}$ for 100 point smoothening. Especially the latter one does highly modify the original response and forms a 'false' peak. Therefore, one has to be very careful when choosing the applied smoothening filter. 100 point smoothening was used here only to better demonstrate the features in Figure 4.18 and Figure 4.19.

\footnotetext{
8 In [Paper 2], $\tau_{\mathrm{dt}}$ is specified with $50 \mathrm{~s}$ and smoothening was performed with 500 points. This is necessary, as the baseline signal exhibits strong noise.

9 In [Paper 1], $\tau_{d t}$ is specified with $60 \mathrm{~s}$. This is due to the smoothing was performed with 100 points.
} 
Table 8: Comparison of the regular $(\tau)$ and derivative $\left(\tau_{d t}\right)$ time constants for different EG decorated materials and test gases.

\begin{tabular}{|c|c|c|c|c|c|c|}
\hline & $\begin{array}{l}\text { Test gas } \\
(\mathrm{ppm})\end{array}$ & $\begin{array}{c}\mathrm{T} \\
\left({ }^{\circ} \mathrm{C}\right)\end{array}$ & $\begin{array}{l}\text { Exp. } \\
\text { time } \\
(\min )\end{array}$ & $\begin{array}{l}\text { UV } \\
(\mathrm{nm})\end{array}$ & $\begin{array}{c}\tau \\
(\mathrm{s})\end{array}$ & $\begin{array}{l}\tau_{\mathrm{dt}} \\
(\mathrm{s})\end{array}$ \\
\hline $\begin{array}{l}\mathrm{Fe}_{3} \mathrm{O}_{4} \\
\mathrm{NP}\end{array}$ & $\begin{array}{c}\mathrm{C}_{6} \mathrm{H}_{6} \\
1\end{array}$ & 150 & 30 & I & 300 & 5010 \\
\hline $\begin{array}{l}\mathrm{Fe}_{3} \mathrm{O}_{4} \\
\mathrm{NP}\end{array}$ & $\begin{array}{c}\mathrm{CH}_{2} \mathrm{O} \\
1\end{array}$ & 150 & 30 & I & 300 & $50^{10}$ \\
\hline $\begin{array}{l}\mathrm{TiO}_{2} \\
\mathrm{NP}\end{array}$ & $\begin{array}{c}\mathrm{O}_{2} \\
10 \%\end{array}$ & 200 & 90 & 265 & 1500 & $25^{11}$ \\
\hline $\begin{array}{l}\mathrm{Fe}_{3} \mathrm{O}_{4} \\
\mathrm{NP}\end{array}$ & $\begin{array}{c}\mathrm{NO}_{2} \\
0.2\end{array}$ & 150 & 15 & I & 250 & 10 \\
\hline $\begin{array}{l}\text { NL } \\
\text { DEG }\end{array}$ & $\begin{array}{c}\mathrm{NH}_{3} \\
25\end{array}$ & 75 & 30 & I & $350-550$ & $15 \pm 5$ \\
\hline $\begin{array}{l}\text { NL } \\
\text { DEG }\end{array}$ & $\begin{array}{c}\mathrm{NH}_{3} \\
25\end{array}$ & 75 & 30 & 265 & $325-500$ & $15 \pm 5$ \\
\hline $\begin{array}{l}\text { NL } \\
\text { DEG }\end{array}$ & $\begin{array}{c}\mathrm{NH}_{3} \\
25\end{array}$ & 75 & 30 & 355 & $325-550$ & $15 \pm 5$ \\
\hline $\begin{array}{l}\text { NL } \\
\text { DEG }\end{array}$ & $\begin{array}{c}\mathrm{C}_{6} \mathrm{H}_{6} \\
0.2\end{array}$ & 150 & 30 & I & $100-200$ & 10 \\
\hline $\begin{array}{l}\text { NL } \\
\text { DEG }\end{array}$ & $\begin{array}{c}\mathrm{CH}_{2} \mathrm{O} \\
0.2\end{array}$ & 150 & 30 & I & $100-400$ & 10 \\
\hline
\end{tabular}

It should be noted that in the practical applications of gas sensors, the change in the gas concentration in the studied environment usually does not occur by leaps and bounds, but rather slowchanging processes. Therefore, the applied method might not be useful for processes where the time constant of the gas concentration change will be close to the time constant of the sensor. One

10 See footnote ${ }^{8}$ on page 67.

${ }^{11}$ See footnote ${ }^{9}$ on page 67. 
method to overcome this issue in real applications would be the use of a sampling pump instead of a continuous gas flow over the sensor. It can also be used as an additional sensor signal to create more transient data which could be used for multivariate statistic analysis to enhance sensitivity.

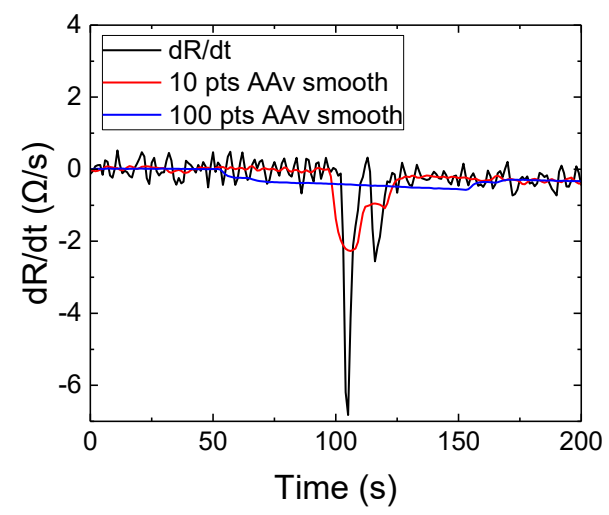

Figure 4.22: Third peak (exposure towards $200 \mathrm{ppb} \mathrm{NO}_{2}$ ) of Figure 4.18 with different adjacent average smoothening filters. 



\section{Conclusions and outlook}

In summary, the work presented in this thesis focused on how to utilize epitaxially grown graphene on $\mathrm{SiC}$ as an ultra-sensitive gas sensor. Three main approaches have been tested and evaluated to increase the sensitivity, selectivity, speed of response and stability of the graphene based gas sensors.

First, the decoration with different metal oxide nanoparticles and nanolayers was investigated. With the iron oxide NP DEG sensor, it was easily possible to detect and quantitatively measure concentrations down to a single ppb of benzene and formaldehyde, making it very promising for air quality monitoring. Several NL DEG samples have been evaluated towards their sensitivity to the two mentioned VOCs and ammonia under varying environmental influences. Again, iron oxide was shown to be a very promising decoration material as that sensor was able to detect trace amounts of ammonia at rather low temperatures with humidity. This could be a very interesting combination for breath analysis applications with focus on ammonia sensing. The integrity of the graphene lattice was maintained after functionalization, which was verified for each sample using characterization methods like AFM, Raman and XPS.

The second approach, using UV irradiation during the measurement, is well known and was also here shown to have a huge impact for some material/gas combinations. For example, the titanium oxide NP DEG sensor was only distinctively sensitive towards changes of oxygen if illuminated with UV light. However, we could also show that UV irradiation is not good for all gas sensors as it can also decrease the sensitivity or simply not affect the measurement at all.

As a last step, the first-order time-derivative was investigated as an alternative sensor signal instead of the sensor's resistance. We could demonstrate that not only a more stable baseline can be 
achieved, but also that the time constants can be drastically reduced as the peak of slope reaches its maximum much faster compared to the resistance value. This peak is concentration dependent and almost independent of exposure and relaxation times. With this method, the time constants can be drastically decreased, which opens an opportunity for rather slow gas sensors in areas where a fast gas sensor readout is compulsory. Moreover, reduced time constants can save lab testing time, thus saving time, resources and money during research activities.

All three investigated methods show very promising results to improve sensing performance, opening new fields of possible sensor applications. More time will be invested to further improve sensitivity, selectivity, speed of response and stability of the graphenebased gas sensors. This can be done, for example, through the exploration of different sensing materials for decoration, but also by using newly developed two-dimensional catalytic metals based on the same SiC bulk. Moreover, with the creation of more transient data, selectivity could be enhanced using multivariate statistic analysis tools. 


\section{References}

[1] World Health Organisation, Ambient air pollution: A global assessment of exposure and burden of disease. Geneva, 2016.

[2] World Health Organisation, "Social media toolkit for Air pollution and Child Health: Prescribing Clean Air Launch," Geneva, 2018.

[3] World Health Organisation, "Economic cost of the health impact of air pollution in Europe: Clean air, health and wealth," Copenhagen, 2015.

[4] B. Szulczyński and J. Gębicki, "Currently Commercially Available Chemical Sensors Employed for Detection of Volatile Organic Compounds in Outdoor and Indoor Air," Environments, vol. 4, no. 21, 2017.

[5] L. Spinelle, M. Gerboles, G. Kok, S. Persijn, and T. Sauerwald, "Review of portable and low-cost sensors for the ambient air monitoring of benzene and other volatile organic compounds," Sensors (Switzerland), vol. 17, no. 7. 2017.

[6] J. Eriksson et al., "Modified Epitaxial Graphene on SiC for Extremely Sensitive and Selective Gas Sensors," Mater. Sci. Forum, vol. 858, pp. 1145-1148, 2016.

[7] P. Clément et al., "Iron oxide and oxygen plasma functionalized multi-walled carbon nanotubes for the discrimination of volatile organic compounds," Carbon N. Y., vol. 78, pp. 510-520, 2014.

[8] J. Gong, Y. Li, X. Chai, Z. Hu, and Y. Deng, "UV-lightactivated $\mathrm{ZnO}$ fibers for organic gas sensing at room temperature," J. Phys. Chem. C, vol. 114, no. 2, pp. 12931298, 2010.

[9] B. Timmer, W. Olthuis, and A. Van Den Berg, "Ammonia sensors and their applications - A review," Sensors Actuators, B Chem., vol. 107, no. 2, pp. 666-677, 2005.

[10] S. Batterman, S. Chambliss, and V. Isakov, "Spatial resolution requirements for traffic-related air pollutant exposure evaluations," Atmos. Environ., vol. 94, pp. 518-528, 2014.

[11] E. Espid and F. Taghipour, "UV-LED Photo-activated Chemical Gas Sensors: A Review," Crit. Rev. Solid State Mater. Sci., vol. 42, no. 5, pp. 416-432, 2017. 
[12] C. H. Wu et al., "Fast gas concentration sensing by analyzing the rate of resistance change," Sensors Actuators, B Chem., vol. 209, pp. 906-910, 2015.

[13] K. S. Novoselov et al., "Electric Field Effect in Atomically Thin Carbon Films," Science (80-. )., vol. 306, pp. 666-669, 2004.

[14] F. Bonaccorso, Z. Sun, T. Hasan, and A. C. Ferrari, "Graphene photonics and optoelectronics," Nat. Photonics, vol. 4, no. 9, pp. 611-622, 2010.

[15] A. H. Castro Neto, F. Guinea, N. M. R. Peres, K. S. Novoselov, and A. K. Geim, "The electronic properties of graphene," Rev. Mod. Phys., vol. 81, no. 1, pp. 109-162, 2009.

[16] J. Lloyd-Hughes and T. I. Jeon, "A review of the terahertz conductivity of bulk and nano-materials," J. Infrared, Millimeter, Terahertz Waves, vol. 33, no. 9, pp. 871-925, 2012.

[17] A. Nag, A. Mitra, and S. C. Mukhopadhyay, "Graphene and its sensor-based applications: A review," Sensors Actuators, A Phys., vol. 270, pp. 177-194, 2018.

[18] J. Huang et al., "Disorder induced Dirac-point physics in epitaxial graphene from temperature-dependent magnetotransport measurements," Phys. Rev. B - Condens. Matter Mater. Phys., vol. 92, no. 7, pp. 1-6, 2015.

[19] E. Mostaani, N. D. Drummond, and V. I. Fal'ko, "Quantum Monte Carlo Calculation of the Binding Energy of Bilayer Graphene," Phys. Rev. Lett., vol. 115, no. 11, pp. 1-5, 2015.

[20] C. Virojanadara, M. Syväjarvi, R. Yakimova, L. I. Johansson, A. A. Zakharov, and T. Balasubramanian, "Homogeneous large-area graphene layer growth on 6H-SiC(0001)," Phys. Rev. B - Condens. Matter Mater. Phys., vol. 78, no. 24, pp. 16, 2008.

[21] C. Riedl, C. Coletti, T. Iwasaki, A. A. Zakharov, and U. Starke, "Quasi-free-standing epitaxial graphene on $\mathrm{SiC}$ obtained by hydrogen intercalation," Phys. Rev. Lett., vol. 103, no. 24, pp. 1-4, 2009.

[22] K. von Klitzing, "The quantized Hall effect," Rev. Mod. Phys., vol. 58, no. 3, pp. 519-531, 1986.

[23] A. Tzalenchuk et al., "Towards a quantum resistance standard based on epitaxial graphene," Nat. Nanotechnol., vol. 5, no. 3, pp. 186-189, 2010. 
[24] S. V. Kopylov, A. Tzalenchuk, S. Kubatkin, and V. I. Fal'ko, "Charge transfer between epitaxial graphene and silicon carbide," Appl. Phys. Lett., vol. 97, no. 11, pp. 11-14, 2010.

[25] F. Schedin et al., "Detection of individual gas molecules adsorbed on graphene," Nat. Mater., vol. 6, no. 9, pp. 652$655,2007$.

[26] R. Pearce, J. Eriksson, T. Iakimov, L. Hultman, A. Lloyd Spetz, and R. Yakimova, "On the differing sensitivity to chemical gating of single and double layer epitaxial graphene explored using scanning kelvin probe microscopy," ACS Nano, vol. 7, no. 5, pp. 4647-4656, 2013.

[27] F. Yavari, E. Castillo, H. Gullapalli, P. M. Ajayan, and N. Koratkar, "High sensitivity detection of NO2 and NH3 in air using chemical vapor deposition grown graphene," Appl. Phys. Lett., vol. 100, no. 20, 2012.

[28] S. S. Varghese, S. Lonkar, K. K. Singh, S. Swaminathan, and A. Abdala, "Recent advances in graphene based gas sensors," Sensors Actuators, B Chem., vol. 218, pp. 160-183, 2015.

[29] A. Berholts, T. Kahro, A. Floren, H. Alles, and R. Jaaniso, "Photo-activated oxygen sensitivity of graphene at room temperature," Appl. Phys. Lett., vol. 105, no. 16, 2014.

[30] F. L. Meng, Z. Guo, and X. J. Huang, "Graphene-based hybrids for chemiresistive gas sensors," TrAC - Trends Anal. Chem., vol. 68, pp. 37-47, 2015.

[31] S. Gupta Chatterjee, S. Chatterjee, A. K. Ray, and A. K. Chakraborty, "Graphene-metal oxide nanohybrids for toxic gas sensor: A review," Sensors Actuators, B Chem., vol. 221, no. 2, pp. 1170-1181, 2015.

[32] Y. You et al., "On the mechanism of gas adsorption for pristine, defective and functionalized graphene," Phys. Chem. Chem. Phys., vol. 19, no. 8, pp. 6051-6056, 2017.

[33] A. P. Lee and B. J. Reedy, "Temperature modulation in semiconductor gas sensing," Sensors Actuators B Chem., vol. 60, no. 1, pp. 35-42, 1999.

[34] C. Bur, "Selectivity Enhancement of Gas Sensitive Field Effect Transistors by Dynamic Operation," Saarland University, Saarbrücken, 2015. 
[35] C. Bur, M. Bastuck, D. Puglisi, A. Schütze, A. Lloyd Spetz, and M. Andersson, "Discrimination and quantification of volatile organic compounds in the ppb-range with gas sensitive SiC-FETs using multivariate statistics," in Sensors and Actuators, B: Chemical, 2015, vol. 214, pp. 225-233.

[36] F. Yavari and N. Koratkar, "Graphene-based chemical sensors," J. Phys. Chem. Lett., vol. 3, no. 13, pp. 1746-1753, 2012.

[37] A. Di Bartolomeo, "Graphene Schottky diodes: An experimental review of the rectifying graphene/semiconductor heterojunction," Phys. Rep., vol. 606, pp. 1-58, 2016.

[38] S. Y. Zhou et al., "Substrate-induced bandgap opening in epitaxial graphene," Nat. Mater., vol. 6, no. 10, pp. 770-775, 2007.

[39] Y. F. Sun et al., "Metal oxide nanostructures and their gas sensing properties: A review," Sensors, vol. 12, no. 3, pp. 2610-2631, 2012.

[40] D. Depla, S. Mahieu, and J. E. Greene, "Sputter Deposition Processes," in Handbook of Deposition Technologies for Films and Coatings, Third., P. M. Martin, Ed. Elsevier, 2010, pp. 253-296.

[41] Y. Yamamura and H. Tawara, "Energy dependence of ioninduced sputtering yields from monatomic solids at normal incidence," At. Data Nucl. Data Tables, vol. 62, no. 2, pp. 149253, 1996.

[42] M. Ohring, Materials Science of Thin Films. Academic Press, 1992.

[43] I. Pilch, D. Söderström, N. Brenning, and U. Helmersson, "Size-controlled growth of nanoparticles in a highly ionized pulsed plasma," Appl. Phys. Lett., vol. 102, no. 3, 2013.

[44] R. Gunnarsson, U. Helmersson, and I. Pilch, "Synthesis of titanium-oxide nanoparticles with size and stoichiometry control," J. Nanoparticle Res., vol. 17, no. 9, pp. 1-11, 2015.

[45] M. Kodu et al., "Graphene-Based Ammonia Sensors Functionalised with Sub-Monolayer V2O5: A Comparative Study of Chemical Vapour Deposited and Epitaxial Graphene," Sensors, vol. 19, no. 4, pp. 1-17, 2019.

[46] M. Rodner, "Lithium doped tungsten oxide films for gas sensor applications,” Saarland University, 2016. 
[47] G. S. Bumbrah and R. M. Sharma, "Raman spectroscopy Basic principle, instrumentation and selected applications for the characterization of drugs of abuse," Egypt. J. Forensic Sci., vol. 6, no. 3, pp. 209-215, 2016.

[48] I. G. Ivanov, J. U. Hassan, T. Iakimov, A. A. Zakharov, R. Yakimova, and E. Janzén, "Layer-number determination in graphene on $\mathrm{SiC}$ by reflectance mapping," Carbon N. Y., vol. 77, pp. 492-500, 2014.

[49] R. M. Petoral, K. Wermelin, E. Dahlstedt, J. Hellberg, and K. Uvdal, "Adsorption of n-butyl-substituted tetrathiafulvalene dodecanethiol on gold," J. Colloid Interface Sci., vol. 287, no. 2, pp. 388-393, 2005.

[50] P. Hohenberg and W. Kohn, "Inhomogeneous Electron Gas," Phys. Rev., vol. 136, no. 3B, pp. 864-871, 1964.

[51] D. J. Frisch, M. J.; Trucks, G. W.; Schlegel, H. B.; Scuseria, G. E.; Robb, M. A.; Cheeseman, J. R.; Scalmani, G.; Barone, V.; Petersson, G. A.; Nakatsuji, H.; Li, X.; Caricato, M.; Marenich, A. V.; Bloino, J.; Janesko, B. G.; Gomperts, R.; Mennucci, B.; Hratch, "Gaussian 16." Gaussian Inc, Wallingford CT, 2016.

[52] Y. Zhao and D. G. Truhlar, "A new local density functional for main-group thermochemistry, transition metal bonding, thermochemical kinetics, and noncovalent interactions," $J$. Chem. Phys., vol. 125, no. 19, 2006.

[53] Y. Zhao and D. G. Truhlar, "The M06 suite of density functionals for main group thermochemistry, thermochemical kinetics, noncovalent interactions, excited states, and transition elements: Two new functionals and systematic testing of four M06-class functionals and 12 other function," Theor. Chem. Acc., vol. 120, no. 1-3, pp. 215-241, 2008.

[54] P. J. Hay and W. R. Wadt, "Ab initio effective core potentials for molecular calculations. Potentials for $\mathrm{K}$ to $\mathrm{Au}$ including the outermost core orbitale," J. Chem. Phys., vol. 82, no. 1, pp. 299-310, 1985.

[55] S. F. Boys and F. Bernardi, "The calculation of small molecular interactions by the differences of separate total energies. Some procedures with reduced errors," Mol. Phys., vol. 19, no. 4, pp. 553-566, 1970. 
[56] A. C. Ferrari et al., "Science and technology roadmap for graphene, related two-dimensional crystals, and hybrid systems," Nanoscale, vol. 7, no. 11, pp. 4598-4810, 2015.

[57] R. Yakimova et al., "Analysis of the Formation Conditions for Large Area Epitaxial Graphene on SiC Substrates," Mater. Sci. Forum, vol. 645-648, pp. 565-568, 2010.

[58] C. Bur, "New method for selectivity enhancement of SiC field effect gas sensors for quantification of NOx," Saarland University, 2012.

[59] A. Lloyd Spetz and M. Andersson, "Technology and Application Opportunities for SiC-FET Gas Sensors," in Solid State Gas Sensors - Industrial Application, M. Fleischer and M. Lehmann, Eds. Berlin: Springer, 2012, pp. 189-214.

[60] M. Leidinger, C. Schultealbert, J. Neu, A. Schütze, and T. Sauerwald, "Characterization and calibration of gas sensor systems at ppb level - A versatile test gas generation system," Meas. Sci. Technol., vol. 29, no. 1, 2018.

[61] N. Helwig, M. Schüler, C. Bur, A. Schütze, and T. Sauerwald, "Gas mixing apparatus for automated gas sensor characterization,” Meas. Sci. Technol., vol. 25, no. 5, 2014.

[62] M. Bastuck, "Improving the Performance of Gas Sensor Systems with Advanced Data Evaluation, Operation, and Calibration Methods," Linköping University, 2019.

[63] World Health Organisation, "Guidelines for Indoor Air Quality: Selected Pollutants," WHO Guidel., vol. 9, p. 454, 2010.

[64] The European Parliament and the Council of the European Union, "Directive 2008/50/EC of the European Parliament and of the Council of 21 May 2008 on ambient air quality and cleaner air for Europe," Off. J. Eur. Communities, pp. 1-43, 2008.

[65] H. Jasuja, G. W. Peterson, J. B. Decoste, M. A. Browe, and K. S. Walton, "Evaluation of MOFs for air purification and air quality control applications: Ammonia removal from air," Chem. Eng. Sci., vol. 124, pp. 118-124, 2015.

[66] S. N. Behera and M. Sharma, "Investigating the potential role of ammonia in ion chemistry of fine particulate matter formation for an urban environment," Sci. Total Environ., vol. 408, no. 17, pp. 3569-3575, 2010. 
[67] European Environment Agency, "Nitrogen oxides (NOx) emissions," Copenhagen, 2014.

[68] The European Parliament and the Council of the European Union, "Directive 2004/42/CE on the limitation of emissions of volatile organic compounds due to the use of organic solvents in certain paints and varnishes and vehicle refinishing products and amending Directive 1999/13/EC," Off. J. Eur. Union, vol. L143, no. 47, pp. 87-96, 2004.

[69] The Council of the European Union, "Council Directive 1999/13/EC of 11 March 1999 on the limitation of emissions of volatile organic compounds due to the use of organic solvents in certain activities and installations," Off. J. Eur. Communities, vol. L85, no. 42, pp. 1-22, 1999.

[70] US Environmental Protection Agency, "40 CFR Part 51, Subpart F - Procedural Requirements," 2018.

[71] D. T. E. D. L. Ministère de l'écologie, du développement durable, "Décret no 2011-1727 du 2 décembre 2011 relatif aux valeurs-guides pour l'air intérieur pour le formaldéhyde et le benzène," 2011.

[72] M. Schiavon et al., "Assessing the air quality impact of nitrogen oxides and benzene from road traffic and domestic heating and the associated cancer risk in an urban area of Verona (Italy)," Atmos. Environ., vol. 120, pp. 234-243, 2015.

[73] G. D. Nielsen, S. T. Larsen, and P. Wolkoff, "Re-evaluation of the WHO (2010) formaldehyde indoor air quality guideline for cancer risk assessment," Arch. Toxicol., vol. 91, no. 1, pp. 35-61, 2017.

[74] D. S. Lee et al., "Raman Spectra of Epitaxial Graphene on SiC and of Epitaxial Graphene Transferred to SiO2," 2008.

[75] A. C. Ferrari, "Raman spectroscopy of graphene and graphite: Disorder, electron-phonon coupling, doping and nonadiabatic effects," Solid State Commun., vol. 143, pp. 47-57, 2007.

[76] C. Bouhafs et al., "Multi-scale investigation of interface properties, stacking order and decoupling of few layer graphene on C-face 4H-SiC," Carbon N. Y., vol. 116, pp. 722$732,2017$.

[77] G. Wang et al., "One-step synthesis of water-dispersible ultra-small $\mathrm{Fe} 3 \mathrm{O} 4$ nanoparticles as contrast agents for $\mathrm{T} 1$ and T2 magnetic resonance imaging," Nanoscale, vol. 6, no. 5, pp. 2953-2963, 2014. 
[78] M. J. Madou and S. R. Morrison, Chemical Sensing with Solid State Devices. San Diego: Academic Press, 1989.

[79] C. Schultealbert, T. Baur, A. Schütze, S. Böttcher, and T. Sauerwald, "A novel approach towards calibrated measurement of trace gases using metal oxide semiconductor sensors," Sensors Actuators B Chem., vol. 239, pp. 390-396, 2017.

[80] N. Barsan and U. Weimar, "Conduction model of metal oxide gas sensors," J. Electroceramics, vol. 7, pp. 143-167, 2001.

[81] E. C. Dickey, O. K. Varghese, K. G. Ong, D. Gong, M. Paulose, and C. a Grimes, "Room Temperature Ammonia and Humidity Sensing Using Highly Ordered Nanoporous Alumina Films," Sensors, vol. 2, pp. 91-110, 2002.

[82] T. Hibbard and A. J. Killard, "Breath ammonia analysis: Clinical application and measurement," Crit. Rev. Anal. Chem., vol. 41, no. 1, pp. 21-35, 2011.

[83] S. Marco and A. Gutierrez-Galvez, "Signal and data processing for machine olfaction and chemical sensing: A review," IEEE Sens. J., vol. 12, no. 11, pp. 3189-3214, 2012. 


\section{Abbreviations}

$\begin{array}{ll}\text { AFM } & \text { Atomic Force Microscopy } \\ \text { AQM } & \text { Air Quality Monitoring } \\ \text { BSSE } & \text { Basis Set Superposition Error } \\ \text { BZ } & \text { Brillouin Zone } \\ \text { CNT } & \text { Carbonanotube } \\ \text { CCD } & \text { Charge-Coupled Device } \\ \text { CVD } & \text { Chemical Vapor Deposition } \\ \text { DEG } & \text { Decorated Epitaxial Graphene } \\ \text { DFT } & \text { Density Functional Theory } \\ \text { DOS } & \text { Density Of States } \\ \text { EG } & \text { Epitaxial Graphene } \\ \text { FET } & \text { Field Effect Transistor } \\ \text { FWHM } & \text { Full Width at Half Maximum } \\ \text { GMA } & \text { Gas Mixing Apparatus } \\ \text { LANL2DZ } & \text { Los Alamos National Laboratory 2 Double-Zeta } \\ \text { LED } & \text { Light Emitting Diode } \\ \text { MFC } & \text { Mass Flow Controller } \\ \text { MOS } & \text { Metal Oxide Semiconductor } \\ \text { NL } & \text { Nanolayer } \\ \text { NP } & \text { Nanoparticle } \\ \text { PEG } & \text { Pristine Epitaxial Graphene } \\ \text { PFA } & \text { Perfluoroalkoxy Alkane } \\ \text { PLD } & \text { Pulsed Laser Deposition } \\ \text { PVD } & \text { Physical Vapor Deposition } \\ \text { QHE } & \text { Quantum Hall Effect } \\ \text { RH } & \text { Relative Humidity } \\ \text { SNR } & \text { Signal to Noise Ratio } \\ \text { UV } & \text { Ultraviolet } \\ \text { VOC } & \text { Volatile Organic Compound } \\ \text { WHO } & \text { World Health Organization } \\ \text { XPS } & \text { X-ray Photoelectron Spectroscopy } \\ & \end{array}$




\section{Papers}

The papers associated with this thesis have been removed for copyright reasons. For more details about these see:

http://urn.kb.se/resolve?urn=urn:nbn:se:liu:diva-160482 


\section{FACULTY OF SCIENCE AND ENGINEERING}

Linköping Studies in Science and Technology, Licentiate Thesis No. 1851, 2019 Department of Physics, Chemistry and Biology (IFM)

Linköping University

SE-581 83 Linköping, Sweden

www.liu.se 